HIAS-E-37

\title{
A Leverage Theory of Tying in Two-Sided Markets
}

Jay Pil Choi

Department of Economics, Michigan State University

Hitotsubashi Institute for Advanced Study, Hitotsubashi University

Doh-Shin Jeon

Toulouse School of Economics, University of Toulouse Capitole (IDEI)

CEPR

November 2016

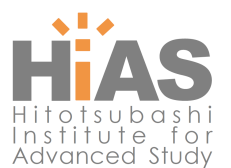

Hitotsubashi Institute for Advanced Study, Hitotsubashi University 2-1, Naka, Kunitachi, Tokyo 186-8601, Japan

tel:+81 425808604 http://hias.ad.hit-u.ac.jp/

HIAS discussion papers can be downloaded without charge from: http://hdl.handle.net/10086/27202

https://ideas.repec.org/s/hit/hiasdp.html

All rights reserved. 


\title{
A Leverage Theory of Tying in Two-Sided Markets*
}

\author{
Jay Pil Choi $\quad$ Doh-Shin Jeon ${ }^{\ddagger}$
}

November 11, 2016

\begin{abstract}
Motivated by the recent antitrust investigations concerning Google, we develop a leverage theory of tying in two-sided markets. In a setting where the "one monopoly profit result" holds otherwise, we uncover a new channel through which tying allows a monopolistic firm in one market to credibly leverage its monopoly power to another competing market if the latter is two-sided. In the presence of the nonnegative price constraint, tying provides a mechanism to circumvent the constraint in the tied product market without inviting an aggressive response by the rival firm. We identify conditions under which tying in two-sided markets is profitable and explore its welfare implications. In addition, we show that our model can be applied more widely to any markets in which sales to consumers in one market can generate additional revenues that cannot be competed away due to non-negative price constraints.
\end{abstract}

JEL Codes: D4, L1, L5

Key Words: Tying, Leverage of monopoly power, Two-sided markets, Zero pricing, Non-negative pricing constraint

${ }^{*}$ We thank Federico Etro, Bruno Jullien, Andras Niedermayer, Volker Nocke, Martin Peitz, Patrick Rey, Kyoungwon Rhee, Chengsi Wang and participants in various conferences and seminars for valuable discussions and comments. Taeyoon Hwang and Sungwook Koh provided excellent research assistance. This work was supported by the Ministry of Education of the Republic of Korea and the National Research Foundation of Korea (NRF-2016S1A5A2A01022389). Jeon acknowledges the financial support of the Jean-Jacques Laffont Digital Chair.

${ }^{\dagger}$ Department of Economics, Michigan State University and Hitotsubashi Institute for Advanced Study, Hitotsubashi University. E-mail: choijay@msu.edu.

¥Toulouse School of Economics, University of Toulouse Capitole (IDEI) and CEPR. E-mail: dohshin.jeon@gmail.com. 


\section{Introduction}

Tying has a long history of scrutiny by antitrust laws and has been harshly treated by courts both in the US and in Europe. Such harsh treatment is based on the belief in the leverage theory of tying, according to which tying provides a mechanism for a monopolist to leverage its monopoly power to monopolize another market where it faces competition. ${ }^{1}$ The theory has been heavily criticized by scholars of the Chicago School (Bork (1954), Director and Levi (1956), Bowman (1957), Posner (1979)), whose argument can be summarized as the well-known "one monopoly profit result"2. Even if there have been attempts to restore the leverage theory against the criticism (such as Whinston 1990 and Nalebuff 2004), these constructions require some relatively strong assumptions (as explained later) and the existing leverage theory does not deal with tying in two-sided markets. Motivated by the recent Google case in Europe and other countries where Google is accused of an abuse of dominance with its practice of bundling applications for Android mobile phones, ${ }^{3}$ we develop a leverage theory of tying in two-sided markets. In a setting in which the "single monopoly profit result" holds if the market of the tied product is one-sided, we uncover a new channel through which a monopolistic firm in one market can credibly leverage its monopoly power to another competing market if the latter is two-sided, which can invalidate the one monopoly profit result.

Our analysis applies when platforms in a two-sided market are constrained to set nonnegative prices on the consumer side. In two-sided markets the need for all sides of the market to engage creates a "chicken and egg" problem (Caillaud and Jullien, 2003) in that members of each group are willing to participate in the market only if they expect many members from the other side to participate. The literature on two-sided markets has analyzed the optimal pricing structure to coordinate the demands of distinct groups of customers and shows that below-cost pricing naturally arises on one side in order to enhance participation because the loss from the below-cost pricing can be recouped on the other side of the market (see Armstrong (2006) and Rochet and Tirole (2006)). When the marginal cost is low as in digital markets, this implies that the optimal pricing strategy entails negative prices. However, we can imagine situations in which negative prices may

\footnotetext{
${ }^{1}$ For instance, the U.S. Supreme Court invoked the leverage theory in declaring block booking (i.e., bundling of movies) illegal in U.S. v. Paramount Pictures (1948) and in U.S. v. Loew's (1962).

${ }^{2}$ See, for instance, Areeda, Kaplow and Edlin (2013) for a discussion of the single monopoly profit theory.

${ }^{3}$ Russian antitrust officials fined Google $\$ 6.8$ million on August 11, 2016 for abusing its market position with its mobile operating system Android. Google is also under investigation in Korea and India.
} 
be impractical due to adverse selection and opportunistic behaviors by consumers (Farrell and Gallini (1988) and Amelio and Jullien, 2012). ${ }^{4}$

We show that tying provides a mechanism to circumvent the non-negative price constraint in the tied product market without inviting an aggressive response by the rival firm if the rival firm's price response to tying faces the non-negative constraint. In our model, the non-negative price constraint plays two roles: 1) it limits competition in the tied good market, which creates additional surplus to extract through tying, and 2) it limits the rival firm's response to tying. In addition, our theory fills the gap in the literature by showing that tying is credible without any commitment mechanism and forecloses the rival in the tied product market regardless of whether the two products tied together are independent or complementary. The credibility of tying can explain the use of contractual tying (such as Google's contract with handset manufacturers) for the leverage purpose. ${ }^{5}$

To see the incentives to leverage monopoly power, consider a monopolist in one market that also competes in a two-sided market with a more efficient rival firm (i.e., a rival platform). The two-sided market consists of consumers on one side and advertisers on the other. We envision a situation in which consumers are competitive bottleneck in the two-sided market (see Armstrong (2006) and Armstrong and Wright (2007)); a platform can extract extra revenues from the advertiser side when it attracts a consumer from the bottleneck side. First, in the absence of tying, the non-negative price constraint limits competition on the consumer side of the two-sided market and generates additional profit for the more efficient rival firm which cannot be competed away. This creates incentives for the monopolistic firm to tie and effectively engage in a negative price in order to capture this extra surplus. Second, when the monopolistic firm tries to steal the additional profit in the two-sided market, tying will induce a more aggressive response by the rival firm as in Whinston (1990). However, the rival firm's ability to respond aggressively can be muted as the non-negative price constraint begins to bind. Thus, the non-negative price constraint in two-sided markets plays the dual role of creating additional surplus and limiting aggressive response by the rival firm, which provides incentives to tie by the monopolistic firm.

\footnotetext{
${ }^{4}$ To quote Farrell and Gallini (1988), "[a]t a negative price, people could take computers at a negative price and use them for landfill (p.679)."

${ }^{5}$ The tying literature distinguishes contractual tying from technical tying: the former can be undone ex post with a relatively low cost while the latter can be undone only with a significant cost. Therefore, technical tying can be used as a device to pre-commit to tying when tying is not ex post credible (Whinston, 1990).
} 
The paper is partly motivated by the recent antitrust investigations concerning Google in Europe and elsewhere. In one of the investigations, the European Commission (EC) is concerned with Google's conduct in relation to applications and services for smartphones and tablets. ${ }^{6}$ In particular, Google has been alleged by rival firms to "illegally hinder the development and market access of rival applications and services by tying or bundling certain Google applications and services distributed on Android devices with other Google applications, services and/or application programing interfaces of Google." ${ }^{7}$ After preliminary investigations, the EC issued a statement of objections on April 20, 2016, informing Google of its view that "the company has, in breach of EU antitrust rules, abused its dominant position by imposing restrictions on Android device manufacturers and mobile network operators." ${ }^{8}$ Even though Google's Android operating system for mobile devices is supposed to be "open," Google effectively implements bundling of its apps through Android's Mobile Application Distribution Agreements (MADA) contracts that force manufacturers to include them and their respective terms in an all-or-nothing fashion. ${ }^{9}$ According to MADA contracts, Android device manufacturers must preinstall all or none of Google apps, depriving them of the ability to mix and match Google apps considered essential with other third-party apps which may be superior to some of the listed Google apps. Even though they are allowed to preinstall competing apps in addition to the listed Google apps with similar functionalities, they are reluctant to do so because of the limited screen space available on devices. In addition, Google requires its apps to be the default in key app categories such as search and location and be placed in prominent positions on the screen. ${ }^{10}$ As a result, the potential for installing multiple apps (i.e., multihoming) to mitigate the effects of tying is somewhat limited (Edelman,

\footnotetext{
${ }^{6}$ The EC's other investigations on Google concern Google's search engine, which has been alleged to bias its search results to promote other revenue-generating Google services such as comparison shopping. See the European Commission Fact Sheet entitled "Antitrust: Commission sends Statement of Objections to Google on comparison shopping service," released on April 15, 2015. Available at http://europa.eu/rapid/press-release_MEMO-15-4781_en.htm

${ }^{7}$ See the European Commission Fact Sheet entitled "Antitrust: Commission opens formal investigation against Google in relation to Android mobile operating system," released on April 15, 2015. Available at http://europa.eu/rapid/press-release_MEMO-15-4782_en.htm

${ }^{8}$ See the European Commission Press Release entitled "Antitrust: Commission sends Statement of Objections to Google on Android operating system and applications," available at http://europa.eu/rapid/press-release_IP-16-1492_en.htm

9 "Devices may only be distributed if all Google Applications [listed elsewhere in the agreement] ... are pre-installed on the Device." See section 2.1 of the MADA between Google and HTC.

${ }^{10}$ For instance, the phone manufacturer must set "Google Search ... as the default search provider for all Web search access points." See MADA Section 3.4(4). The same requirement applies to Google's Network Location Provider service.
} 
2015). ${ }^{11}$ The EC's analysis in relation to the investigation of Google also indicates that "consumers rarely download applications that would provide the same functionality as an app that is already pre-installed (unless the pre-installed app is of particularly poor quality)."12 The tying mechanism we uncover can be applied to the Google Android case and can explain why Google has an incentive to tie. We further show that such tying arrangements can lead to the exclusion of (more efficient) rival firms, providing a theory of harm associated with Google's practices in the MADA contracts. ${ }^{13}$

In Section 2, we present our mechanism of tying in the baseline model of homogenous consumers. In a setting in which the well-known "single monopoly profit result" holds if the tied market are one-sided (or in the absence of the non-negative price constraint), we show that the interplay between two-sidedness of the tied market and the non-negative pricing constraint breaks the result and restores an incentive to tie to leverage monopoly power into the tied two-sided market. In addition, this mechanism is robust even when consumers can multi-home (section 2.2) and when the bundled products are perfect complements instead of having independent values (section 2.3). Moreover, our insight can be more widely applied to any markets in which sales to consumers in one market can generate additional revenues that cannot be competed away due to non-negative price constraints. Specifically, even if the tied market is one-sided, additional revenue can be generated in an intertemporal context from the same market in the future in the presence of network effects or switching costs (section 2.4). We also briefly discuss how we can modify the model to be applied to the Google case (section 2.5) because app developers can make payments to original equipment manufacturers (OEMs) to have their apps to be pre-installed, which makes the non-negative price assumption less applicable to OEMS.

In Sections 3 and 4, we extend the baseline model by incorporating heterogenous consumers in the tying market. This allows us to check the robustness of our insight obtained from the baseline model and also addresses the question of how the degree of two-sidedness of the tying market affects the incentive to tie. ${ }^{14}$ Sections 3 and 4 differ

\footnotetext{
${ }^{11}$ For a discussion of how to apply antiturst law to zero-price markets, including the issues of market definition and market power, from the legal perspective, see Newman (2015, 2016).

${ }^{12}$ See the European Commission - Fact Sheet entitled "Antitrust: Commission sends Statement of Objections to Google on Android operating system and applications,' released on April 20, 2016. Available at http://europa.eu/rapid/press-release_MEMO-16-1484_en.htm.

${ }^{13}$ For a detailed discussion of the key aspects of Google's practices and their potentially exclusionary effects in the mobile phone industry from a legal perspective, see Edelman and Geradin (2016).

${ }^{14}$ In the baseline model of homogenous consumers, the incentive to tie does not depend on the degree of two-sidedness of the tying market.
} 
in that we introduce intergroup network effects in the tied market in Section 4 while no network effect is introduced in Section 3.

More specifically, in section 3 we assume that consumers are bottleneck both in the tying and in the tied two-sided markets. For example, the other side interacting with consumers in both markets could be advertising. In such a case, we find that the incentive to tie increases with the degree of two-sidedness of the tied market but decreases with the degree of two-sidedness of the tying market, where the two-sidedness is represented by the importance of advertising revenues. For instance, when the tying market is sufficiently two-sided while the tied market is close to being one-sided, tying reduces both firms' profits as in Whinston (1990). Under tying, consumers whose valuations for the monopoly product are low enough prefer buying the competing tied product instead of the bundle. This means that the tying firm loses the advertising revenue in the tying market from these consumers. This loss increases with the degree of two-sidedness of the tying market. As our model in Section 3 includes tying in one-sided markets as a special case, it also captures various motives for tying identified by the previous literature in one-sided markets.

Section 4 introduces cross-group network effects in the tied market while maintaining heterogenous consumers in the tying market. For instance, the other side in the tied market could be applications. Consumers' benefits increase with the number of applications and application developers' benefits increase with the number of consumers. When there is no tying, the network effects generate a tipping equilibrium toward the more efficient rival platform in the tied market. However, tying can generate a tipping toward the tying platform and such tipping is more likely as the two-sidedness of the tying market increases. Intuitively, when the tying market becomes more two-sided, the tying platform becomes more aggressive in pricing in order to capture more consumers in the tying market, which generates a larger network effect and hence makes tipping more likely in the tied market. When tipping occurs, there is no loss of advertising revenue in the tying market and therefore the incentive to tie increases with the degree of two-sidedness of the tying market. In addition, we show that this insight is robust to an interior equilibrium in which the tying platform occupies a large consumer market share. We expect that a similar insight can be applied to when the tying market (or both the tying and the tied markets) exhibits cross-group network effects.

Our paper contributes to the literature on the leverage theory of tying, which has been extensively studied. In a classical paper on tying, Whinston (1990) shows that selling a monopolized primary product and an unrelated differentiated product together 
as a bundle may allow the monopolist to commit to a more aggressive pricing strategy, preventing entry in the differentiated market. In Carbajo, De Meza, and Seidman (1990), on the other hand, bundling is used as a strategy to segment the market and relax price competition. ${ }^{15}$ By considering a model in which each of the tying and the tied markets can be one-sided or two-sided, our paper encompasses both Whinston's and Carbajo et al.'s results as special cases. In particular, when the tied market is two-sided, we uncover a new channel through which tying is profitable at the expense of rival firms. We emphasize that our leverage mechanism does not have any credibility issue in sharp contrast to Whinston (1990) and Nalebuff (2004). Our mechanism thus does require neither technical tying as a commitment device as in Whinston (1990) nor the controversial assumption that the tying firm is a Stackelberg leader in setting prices as in Nalebuff (2004) ${ }^{16}$ We show that a monopolist's tying is credible and reduces the rival's profit if the tied market is two-sided, which provides a justification for the use of contractual tying. We further show that tying is credible and forecloses the rival even in the case of perfect complements. This result is noteworthy because it is known that a monopolist selling a perfectly complementary product has no incentive to practice tying to exclude the rival (Proposition 3 of Whinston, 1990).

Choi and Stefanadis (2001) and Carlton and Waldman (2002) provide a dynamic leverage theory of tying. In Choi and Stefanadis (2001), the probability of successful entry depends on the level of $\mathrm{R} \& \mathrm{D}$ expenditures. When an incumbent monopolist in two complementary components practices bundling, it makes entry in one component completely dependent upon success in the other. By making the prospects of investment less certain, bundling discourages rivals from investing and innovating. Carlton and Waldman (2002) construct a model of bundling with dynamic entry deterrence. In their two-period model, the incumbent initially has a monopoly position in both the primary and the complementary market. There is a potential rival that has the opportunity to enter the complementary market in period 1 and the primary market in period 2.

\footnotetext{
${ }^{15}$ See also Chen (1997).

${ }^{16}$ A notable exception is Peitz (2008), who points out the credibility issue and builds an example in which a monopolist's tying is credible and reduces the rival's profit. Hurkens, Jeon and Menicucci (2016) restores credibility by considering that the tying firm is not a monopolist but a dominant firm facing competition in the tying market. In the context of competition among product portfolios in a common agency setting, Jeon and Menicucci $(2006,2012)$ find that pure bundling is credible as it reduces competition among the products within a firm's portfolio but that competitive bundling leads to efficient outcome if the buyer has no budget constraint (otherwise, bundling builds an entry barrier since it allows firms with large portfolios to capture all the budget).
} 
Furthermore, the potential rival can recoup its fixed cost of entry into the complementary market only by actively operating in both periods. By practicing bundling, the incumbent prevents the competitor's complementary component from having access to customers in period 1, permanently blocking the product's introduction. As a result, the rival also refrains from entering the primary market; entry without a complementary component would not be profitable. The incumbent maintains its monopoly profits in both periods. However, most papers in the literature consider one-sided markets. We show how the two-sidedness of markets in conjunction with the non-negative price constraint generates a new channel through which monopoly power in one market can be leveraged into another.

Amelio and Jullien (2012) analyze the effects of tying in two-sided markets. They consider a situation in which platforms would like to set prices below zero on one side of the market to solve the demand coordination problem in two-sided markets, but are constrained to set non-negative prices. In the analysis of Amelio and Jullien, tying can serve as a mechanism to introduce implicit subsidies on one side of the market in order to solve the aforementioned coordination failure in two-sided markets. As a result, tying can raise participation on both sides and can benefit consumers in the case of a monopoly platform. In a duopoly context, however, tying also has a strategic effect on competition. They show that the effects of tying on consumer surplus and social welfare depend on the extent of asymmetry in externalities between the two sides. Their paper and ours are very different in terms of focus and mechanisms through which tying affects competition. Their main focus is to compare the effects of tying across different market structures (monopolistic vs. duopolistic) whereas our focus is on the leverage of monopoly power in two-sided markets. Choi (2010) also analyzes tying in two-sided markets. However, his focus is on the role of multi-homing. In particular, he shows that tying can be welfareenhancing if multi-homing is allowed, even in cases where its welfare impacts are negative in the absence of multi-homing.

Finally, Iacobucci (2014) develops a similar idea to our mechanism. In particular, he argues that the elimination of competition via tying of two platforms in one side of the market can expand the set of customers to whom the tying firm can sell in the other side of the market. This is similar to our mechanism in which capturing the customer side provides additional revenue from the advertiser side. However, he does not provide a formal analysis as his argument is based on a numerical example. In addition, his logic breaks down when the non-negative price constraint is not binding as the same effects can be achieved by an appropriate pricing scheme without the use of 
tying. This is due to his implicit assumption that firms set prices equal to marginal costs in a competitive equilibrium. However, in the context of complementary products envisioned in his model, the equilibrium price in each component market need not be equal to marginal cost because it is the total price, not the two individual prices, that matters for complementary products. In contrast, we provide a rigorous and formal analysis of tying that fully accounts for intricacies of two-sided markets.

The rest of the paper is organized in the following way. In section 2, we present the baseline model of homogenous consumers to highlight the main essence of the leverage mechanism in two-sided markets and the importance of the non-negative price constraint. After establishing the robustness of our mechanism to multihoming and perfect complements, we demonstrate the applicability of our framework to other types of markets with auxiliary revenues. In section 3, we extend the baseline model by introducing heterogenous consumers in the tying market and investigate how the two-sidedness of both the tying and tied product markets interact to draw policy implications. In Section 4, we consider a model with inter-group network effects in the tied good market. We provide concluding remarks in section 5. Detailed proofs are relegated to the Appendix.

\section{The Baseline Model of Homogenous Consumers}

To show how the interaction between the two-sidedness of markets and the non-negative price constraint generates new incentives to tie, we start by analyzing a simple baseline model of homogenous consumers. In order to highlight the leverage mechanism in twosided markets, we consider a setting in which the well-known "single monopoly profit" result holds and hence the extension of monopoly power from one market to another is not possible in the benchmark without two-sided markets.

Consider two markets, $A$ and $B$. We build a simple framework to analyze tying as a leverage mechanism when both markets are characterized as two-sided. More specifically, in each market there are three classes of agents. There are two distinct customer groups (consumers and advertisers) that interact with each other and intermediaries which enable these two groups to "meet" with each other. In the example of the Internet search market, the two customer groups can be described as advertisers and consumers (who search for information through the Internet). The intermediaries are search engine providers such as Google and Bing. We assume that the two markets are independent in the sense that the value that each consumer (or advertiser) derives from participating in a market is 
independent of whether he or she participates in the other market.

To analyze incentives to leverage market power, we assume that market $A$ is served by firm 1 , a monopolistic platform, and entry to market $A$ is not possible. In contrast, two platforms, firm 1 and firm 2, compete in market $B$. More specifically, we envision a competitive bottleneck situation in which platforms provide services (such as Internet search and video streaming) to consumers and use the customer base to derive advertising revenues from advertisers who need access to consumers. There is a mass one of identical consumers, who have a unit demand for each service/product. To focus on the strategic motive for bundling, we assume that there is no cost advantage or disadvantage associated with bundling.

In market $A$, each consumer's reservation value is denoted by $u$. In market $B$, each consumer's willingness to pay for each firm's product is given by $v_{1}$ and $v_{2}$, respectively, where $\Delta \equiv v_{2}-v_{1}>0$. For most of the paper, we assume that each consumer buys only one of the two products in market $B$ and normalize firms' production costs to zero in all markets. ${ }^{17}$ This single-homing assumption is relaxed in Section 2.2. Each consumer yields additional profit of $\alpha \geq 0$ and $\beta \geq 0$ to the advertiser side in market $A$ and $B$, respectively. If $\alpha=0$, the tying market is one-sided and if $\beta=0$, the tied market is one-sided.

\subsection{The Leverage Mechanism with the Non-Negative Price Constraint in Two-Sided Markets}

Consider the benchmark in which both markets are one-sided (i.e., $\alpha=\beta=0$ ). If these products are sold independently without tying, firm 1 will charge $p_{1}^{A}=u$ in its monopolized market $A$. In market $B$, both firms compete in prices and the equilibrium prices are given by $p_{1}^{B}=0$ and $p_{2}^{B}=\Delta$, where $\Delta \equiv v_{2}-v_{1}>0$. All consumers buy from firm 2. Each firm's profits are given by

$$
\begin{aligned}
& \Pi_{1}=\pi_{1}^{A}+\pi_{1}^{B}=u+0=u \\
& \pi_{2}^{B}=\Delta .
\end{aligned}
$$

\footnotetext{
${ }^{17}$ This is not an innocuous normalization assumption with the non-negative price constraint because it also implies no below-cost pricing. However, as long as production costs are not too high (as would be the case for digital goods), our results would be robust even if we allow below-cost pricing. More importantly, we can derive qualitatively similar results when we introduce asymmetry between the two firms in market $B$ in terms of production costs rather than product qualities.
} 
Now suppose that firm 1 ties its monopolized product $A$ with product $B 1$. Let $\widetilde{P}$ and $\widetilde{p}_{2}$ denote the bundle price and firm 2's price for product $B$ under tying. ${ }^{18}$ We assume that a consumer buys either the $(A, B 1)$ bundle or product $B 2$ : this assumption is relaxed by allowing multi-homing in section 2.2. Then, firm 1 will be able to sell its bundled products only if

$$
u+v_{1}-\widetilde{P} \geq v_{2}-\widetilde{p}_{2} .
$$

Since firm 2 will be willing to set the price as low as its marginal cost, which is zero, the maximum price firm 1 can charge for its bundle in order to make sales is given by $\widetilde{P}=u-\Delta$. Under tying, firm 1's profit is given by

$$
\widetilde{\Pi}_{1}=\max [u-\Delta, 0]
$$

which is less than the profit without tying as $\widetilde{\Pi}_{1}=\max [u-\Delta, 0]<u=\Pi_{1} \cdot{ }^{19}$ Thus, even if tying provides a mechanism to capture the tied good market, it is a Pyrrhic victory as it reduces firm 1's profits. Thus, the monopoly firm has no incentives to tie to extend its market power to the other market. This is the essence of the Chicago school's criticism of the leverage theory of tying. However, this conclusion can be overturned if the tied good market $B$ is two-sided.

Suppose now that market $B$ is two-sided while market $A$ is one-sided. Assume that the advertising revenue is large enough in market $B$ such that $\beta>\Delta$ holds. ${ }^{20}$ Due to this additional revenue source, now each firm in market $B$ is willing to set its price below its marginal cost on the consumer side up to $\beta$. We, however, put a non-negative price restriction that the market prices cannot be negative. Thus, in the absence of tying, once again firm 1 charges a price of $p_{1}^{B}=0$ and firm 2 will set the price of $p_{2}^{B}=\Delta$. Firm 1's profit in market $B$ is zero. However, note that firm $2^{\prime}$ profit is given by $\pi_{2}^{B}=\Delta+\beta$ due to the additional revenue from the advertiser side.

Now suppose that firm 1 ties its monopolized product with product $B$ on the consumer side. Assume $u>\Delta$ such that firm 1 can conquer market $B$ by tying. Once again, the maximum bundle price that enables the tying firm to make sales is given by $\widetilde{P}=u-\Delta$. However, due to the additional revenue source in market $B$, the tying firm's profit now

\footnotetext{
${ }^{18}$ We denote variables under the tying regime with a tilde $(\sim)$.

${ }^{19}$ If $v_{1} \geq v_{2}$, firm 1 's profit with tying is the same as the one without tying.

${ }^{20}$ According to the estimates by financial analyst Richard Windsor, Google made about $\$ 11$ billion in 2015 from advertising sales on Android phones through its apps such as Maps, Search and Gmail. See Chee (2016).
} 
becomes $\widetilde{\Pi}_{1}=u+(\beta-\Delta)>u=\Pi_{1}$. Hence, tying is profitable if the tied good market is two-sided.

This simple model also illustrates the importance of the non-negative price constraint for the two-sidedness of the market to restore incentives to tie. ${ }^{21}$ To see this, suppose that firms can charge a negative price. Then, after tying firm 2 would be willing to set the price as low as $-\beta$. Thus, the maximum bundle price that enables the tying firm to make sales is now given by $\widetilde{P}=u-\Delta-\beta$. As a result, the tying firm's profits is now reduced to $\widetilde{\Pi}_{1}=u-\Delta<u=\Pi_{1}$ as in the Chicago school benchmark case above.

Finally, we can consider the case in which the tying market is two-sided (i.e., $\alpha>0$ ). This would increase firm 1's profit by $\alpha$ regardless of tying as long as it sells its monopoly product. Hence, whether the tying market is one-sided or two-sided does not affect the incentive to tie.

Summarizing, we have:

Proposition 1. Consider the baseline model of homogenous consumers in which products have independent values.

(i) Tying is never profitable and hence the single monopoly profit result holds either if the tied-market is one-sided or if firms can charge negative prices.

(ii) Suppose $u>\Delta$. Tying is profitable if the tied-market is two-sided such that $\beta>\Delta$ holds and firms cannot charge negative prices. Then, tying reduces both firm 2's profit and social welfare, but increases consumer surplus.

(iii) Whether the tying market is one-sided or two-sided does not affect the above results.

Our simple model demonstrates two important differences between the case of a onesided tied product and that of a two-sided tied product, both of which are generated by the non-negative price constraint. First, in the absence of tying, firm 2 realizes a profit beyond its competitive advantage: its profit per consumer is larger than $\Delta$ by $\beta$, which cannot be competed away due to the binding non-negative price constraint that firm 1 faces. This creates an incentive for firm 1 to practice tying in order to subsidize its product $B$ by circumventing the constraint of non-negative pricing. Second, when firm 1 practices tying and is effectively engaging in negative pricing for the tied product, firm 2 would respond more aggressively against tying. However, its aggressive response can be limited

\footnotetext{
${ }^{21}$ Our leverage theory can also be applied to other kinds of price restrictions such as price regulations that prohibt a price below a certain level.
} 
as firm 2 hits the zero price floor even though it is willing to set a price as low as $-\beta$. Therefore, tying in two-sided markets can be immune to an aggressive price response by the rival firm because the non-negative price constraint limits an aggressive response. ${ }^{22}$

Tying reduces welfare as it induces consumers to consume the inferior product of firm 1 instead of the superior product of firm 2 in market $B$. This force will be preserved in any extension. However, tying may increase welfare by expanding the sale of the monopoly product, which we examine in a model of heterogenous consumers in market $A$, in the next section.

Two remarks are in order. First, the result in Proposition 1(ii) that tying increases consumer surplus has to do with the fact that tying reduces firm 2's price from $\Delta$ to zero and results from the assumption of homogenous consumers. Instead, if consumers are heterogenous in terms of their valuations of firm 2's product, then firm 2 may find it optimal to charge a zero price in the absence of tying because of the advertising revenue. In this case, tying will not affect the price charged by firm 2 and hence will not increase consumer surplus. Second, for a similar reason, Proposition 1(iii) is likely to be an artifact of the assumption of homogenous consumers. In order to investigate how the degree of two-sidedness in the tying market (captured by $\alpha$ ) affects firm 1's incentive to tie, we consider heterogenous consumers in the tying market in Sections 3 and 4.

\subsection{Extension to Multihoming}

Up to now, we have assumed that multihoming is impossible. We here allow consumers to do multihoming at some cost. Let $m$ denote the multihoming cost. Consumers are heterogenous in terms of the multihoming cost, which is assumed to be distributed over $[0, \bar{m}]$ according to distribution $G($.$) with strictly positive density g($.$) , where \bar{m}=\infty$ is allowed. In addition, assume that the density function $g($.$) is log-concave and$

$$
\bar{m}>\Delta, G(\Delta) / g(\Delta) \leq \beta
$$

With a log-concave density function, $G(.) / g($.$) is increasing. Thus, G(\Delta) / g(\Delta) \leq \beta$ means that the revenue from the advertising side is large enough in market $B$ compared to the degree of superiority of firm 2's product $\Delta$. Note that the introduction of multihoming

\footnotetext{
${ }^{22}$ In the actual Google case, competition in search engines takes place mainly with payments to OEMs for pre-installation of the applications (not to consumers), which can be at odds with our assumption of non-negative pricing. We address this issue in sectioin 2.5 .
} 
does not affect the analysis of no tying as there is no multihoming. We below extend the tying analysis of Section 2.1. Consider $\alpha=0$ and $\beta>0 .{ }^{23}$

Our analysis shows that the equilibrium prices with multi-homing are the same as those in the previous analysis where multihoming is not feasible. We thus have the following proposition.

Proposition 2. Consider the baseline model of homogenous consumers in which products have independent values. Suppose that multi-homing is possible.

(i) Without tying, all consumers use the superior product of firm 2 in market $B$ and no consumers multi-home.

(ii) With tying, the equilibrium prices are given by $\widetilde{P}=u-\Delta$ and $\widetilde{p}_{2}=0$. Consumers whose multi-homing cost is less than $\Delta$ multi-home. Tying is profitable if $\beta>\frac{\Delta}{[1-G(\Delta)]}$, that is, $\beta$ is relatively large compared to $\Delta$. Social welfare always decreases with tying even though consumers are better off.

Proof. See the Appendix.

Proposition 2 indicates that Proposition 1(ii) naturally extends and is robust to the possibility of multi-homing. Introducing multihoming does not affect the equilibrium prices and those whose multihoming cost is above $\Delta$ buy only the bundle (while all the others multihome). Tying reduces welfare because single-homing consumers use the inferior tied product while those who multihome incur the cost of multihoming. However, tying increases every consumer's surplus at the expense of firm 2, as firm 2 charges a zero price and captures a smaller market share. More precisely, in the absence of tying each consumer has a surplus of $v_{1}$. Under tying with multi-homing, a consumer receives a surplus of $v_{1}+\Delta+\max [0, \Delta-m]$. Firm 2's profits decrease from $(\Delta+\beta)$ to $G(\Delta) \beta$.

In the rest of the paper, we maintain the single-homing assumption.

\subsection{Extension to Perfect Complements}

We show that our leverage mechanism can also be applied when the tying and the tied products are complements. Suppose that the monopoly product $A$ of firm 1 and product $B$ are perfect complements that need to be used together. Consumers can use one of the two system products, $(A, B 1)$ and $(A, B 2)$, depending on which firm's product $B$ is

\footnotetext{
${ }^{23}$ Analyzing the case of $\alpha>0$ does not affect the result because firm 1's profit increases by the same amount of $\alpha$ with or without tying.
} 
used. Consumers' valuation for system $(A, B i)$ is given by $u+v_{i}$, where $i=1,2$ and $\Delta \equiv v_{2}-v_{1}>0$. Once again, we demonstrate that the non-negative price constraint (in conjunction with the two-sidedness of the tied good market) can create incentives to tie even for the perfect complements case. Assume $\alpha=0 .{ }^{24}$

As a benchmark, consider first the case in which the non-negative price constraint is not binding. Without tying, firms are willing to cut the price down to $-\beta$ for product $B$ and firm 2's profit can never be larger than $\Delta$. In fact, there is a continuum of Nash equilibria due to firm 1's ability to "price squeeze" and extract a portion of the surplus $\Delta$ (Choi and Stefanadis, 2001). More precisely, there is a continuum of equilibria parameterized by $\lambda \in[0,1]$, which represents the degree of price squeeze exercised by firm 1 :

$$
\widehat{p}_{1}^{A}=u+v_{1}+\beta+\lambda \Delta, \widehat{p}_{1}^{B}=-\beta, \widehat{p}_{2}^{B}=-\beta+(1-\lambda) \Delta
$$

In equilibrium, consumers purchase the system that includes $B 2 .{ }^{25}$ Firm 1's profit is $\Pi_{1}=\widehat{p}_{1}^{A}=u+v_{1}+\beta+\lambda \Delta$ and firm 2's profit is $\pi_{2}=\widehat{p}_{2}^{B}+\beta=(1-\lambda) \Delta$. It can be easily verified that no firm has an incentive to deviate because they jointly extract the full surplus from consumers.

With tying, only system $(A, B 1)$ is available to consumers since products $A$ and $B$ are perfect complements. Firm 1's profit under tying is $\widetilde{\Pi}_{1}=u+v_{1}+\beta\left(<\Pi_{1}\right)$ while firm 2 's profit is zero. Therefore, for any $\lambda \in[0,1]$, firm 1 has no incentive to practice tying to exclude the superior complementary product of the rival firm. This result reconfirm's Whinston 's (1990) finding (i.e., Proposition 3, p.851) and lends support to the Chicago school's criticism of the leverage theory. ${ }^{26}$

Consider now the case in which the non-negative price constraint is binding. Without tying, once again, we have a continuum of equilibria parameterized by $\lambda \in[0,1]$ :

$$
p_{1}^{A}=u+v_{1}+\lambda \Delta, p_{1}^{B}=0, p_{2}^{B}=(1-\lambda) \Delta .
$$

\footnotetext{
${ }^{24}$ As in the analysis of multi-homing, adding $\alpha>0$ does not affect the analysis.

${ }^{25}$ We adopt the standard tie-breaking convention that if a consumer is indifferent between buying product $B$ from firms 1 and 2, he will buy from firm 2 (the high-quality product producer) because this convention is equivalent to defining price equilibrium as the limit in which prices must be named in some discrete unit of account of size $\epsilon$ as $\epsilon \rightarrow 0$.

${ }^{26}$ For instance, according to Posner (1976, p. 173), "[A fatal] weakness of the leverage theory is its inability to explain why a firm with a monopoly of one product would want to monopolize complementary products as well. It may seem obvious ... but since the products are by hypothesis used in conjunction with one another ... it is not obvious at all."
} 
The non-negativity constraint binds for firm 1's product $B$ (i.e., $p_{1}^{B}=0$ ). As a result, consumers prefer buying $B 2$ at any price $p_{2}^{B}$ smaller than $\Delta$. This means that firm 2 captures the advertising revenue $\beta$ while firm 1 can extract $\lambda \in[0,1]$ fraction of $\Delta$ from firm 2 . Hence, each firm's profit without tying is given by:

$$
\Pi_{1}=u+v_{1}+\lambda \Delta, \pi_{2}=p_{2}^{B}+\beta=(1-\lambda) \Delta+\beta .
$$

With tying, firm 1 can charge $\widetilde{P}=u+v_{1}$ and receives a profit of $\widetilde{\Pi}_{1}=\widetilde{P}+\beta=u+v_{1}+\beta$ and firm 2's profit is zero. Hence, as long as $\beta>\Delta$, firm 1 has an incentive to tie regardless of the value of $\lambda$.

Summarizing, we have:

Proposition 3. Consider the extension of the baseline model of homogenous consumers to perfect complements.

(i) If firms can charge negative prices, tying is never profitable regardless of whether the tied-market is one-sided or two-sided.

(ii) If firms cannot charge negative prices and the tied-market is two-sided enough (i.e., $\beta>\Delta$ ), tying is profitable regardless of the degree of price squeeze prevailing in the absence of tying.

We provide a novel mechanism for leveraging monopoly power though tying for the case of perfect complements; to the best of our knowledge, such theory has not been developed yet in the previous literature. For instance, our theory may be applied to the Microsoft tying cases in which the operating system was bundled together with other complementary applications such as a web browser and a media player. Our theory also exposes the flaw in the reasoning of Iacobucci (2014) who proposes a theory of tying for perfect complements in two-sided markets: the two-sidedness is a necessary condition for tying to be credible, but not a sufficient condition because it should be combined with the non-negativity constraint in pricing as we have shown above.

\subsection{Applications to Other Markets with Ancillary Revenues}

We have developed a leverage theory of tying in the context of two-sided markets. However, our insight can be applied to any market in which sales to consumers in one market can generate additional revenues that cannot be competed away due to non-negative price constraints. This additional revenue came from the other side of the market in the case 
of a two-sided market. The additional revenues can also be generated in an intertemporal context with the other market being the same market in the future. To illustrate this idea, we present two variations of the baseline model with $\alpha=\beta=0$.

\subsubsection{Tying in Markets with (Direct) Network Effects}

Market $A$ is the same as in the baseline model. Market $B$ is characterized with network effects. We adopt a simplified and modified version of Katz and Shapiro's (1986) dynamic technology adoption model with network effects for market $B$. Let us assume a stationary environment with respect to both firms' technologies. ${ }^{27}$ There are two periods. In period $t(=1,2), N^{t}$ consumers of generation $t$ make a purchase decision. For simplicity, assume $N^{1}=N^{2}$. Each period, two firms compete with incompatible products $B 1$ and $B 2$. A consumer who purchases product $B 1$ in period $t$ derives net benefits of $v_{1}+\phi\left(x^{1}+x^{2}\right)-p_{1}^{t}$, and the corresponding value from product $B 2$ is given by $v_{2}+\phi\left(y^{1}+y^{2}\right)-p_{1}^{t}$, where $x^{t}$ and $y^{t}$ denote the quantities of product $B 1$ and $B 2$, respectively, sold in period $t$. Consumers have the same preferences and coordinate on the Pareto-efficient outcome when there are multiple equilibria. Once again, firms' production costs are zero in all markets and $\Delta=v_{2}-v_{1}>0$.

In the absence of tying, firm 1 charges a price of $p_{1}^{A}=u$ in its monopolized market $A$. In market $B$, suppose that firm 1 has captured market $B$ in the first period. This confers firm 1 an installed-base advantage in period 2. Let us assume that this installed-base advantage is sufficiently large such that $\phi^{b}-\phi^{2}>\Delta$, where $\phi^{b}=\phi\left(N^{1}+N^{2}\right)$ and $\phi^{t}$ $=\phi\left(N^{t}\right)$. Then, firm 1 will be able to maintain its market dominance with a price of $\left(\phi^{b}-\phi^{2}\right)-\Delta$. If firm 2 has captured market B in the first period, it can maintain the dominance at a price of $\left(\phi^{b}-\phi^{2}\right)+\Delta$.

Now consider market competition in the first period. If firm 2 decides to capture the market in period 1 , its price needs to satisfy

$$
v_{1}+\phi^{b}-p_{1}^{1} \leq v_{2}+\phi^{b}-p_{2}^{1} .
$$

Firm 1 is willing to charge a price equal to $-\delta\left[\left(\phi^{b}-\phi^{2}\right)-\Delta\right]<0$. However, the nonnegative price constraint limits its price at zero. Given this, firm 2 is able to sell at a

\footnotetext{
${ }^{27}$ In contrast, Katz and Shapiro (1986) assume a situation in which one technology is better than the other in the first period but becomes inferior in the second period to derive interesting dynamics.
} 
price of $\Delta$ in the first period. As a result, each firm's overall profit is given by

$$
\begin{aligned}
& \Pi_{1}=(1+\delta) u \\
& \pi_{2}^{B}=\Delta+\delta\left[\left(\phi^{b}-\phi^{2}\right)+\Delta\right] .
\end{aligned}
$$

Now suppose that firm 1 ties its monopolized product $A$ with product $B 1$. Consider a subgame in which all consumers bought the bundle. Let $\widetilde{P}^{2}$ and $\widetilde{p}_{2}^{2}$ denote the bundle price and firm 2's price for product $B$ in period 2 under tying. Then, firm 1 will be able to sell its bundled products if

$$
u+v_{1}+\phi^{b}-\widetilde{P}^{2} \geq v_{2}-\widetilde{p}_{2}^{2}+\phi^{2} .
$$

Since firm 2 will be willing to set the price as low as its marginal cost, which is zero, the maximum price firm 1 can charge for its bundle in order to make sales is given by $\widetilde{P}^{2}=u-\Delta+\left(\phi^{b}-\phi^{2}\right)$. Under tying, firm 1's profit in the second period is given by

$$
\widetilde{\Pi}_{1}^{2}=u-\Delta+\left(\phi^{b}-\phi^{2}\right)>u
$$

If consumers bought from firm 2 in period 1 , the maximum price firm 1 can charge for its bundle in order to make sales is given by $\widetilde{P}^{2}=u-\Delta-\left(\phi^{b}-\phi^{2}\right)$, which is assumed to be positive with a sufficiently high $u$. Firm 1's profit in period 2 in this subgame is given by

$$
\widetilde{\Pi}_{1}^{2}=u-\Delta-\left(\phi^{b}-\phi^{2}\right)
$$

Consider competition in period 1 under tying. If firm 1 decides to capture the market in period 1 , its price needs to satisfy

$$
u+v_{1}+\phi^{b}-\widetilde{P}^{1} \geq v_{2}+\phi^{1}-\widetilde{p}_{2}^{1} .
$$

Note that $\phi^{b}$ is present on the LHS but $\phi^{1}$ on the RHS because firm 1 captures the second period market regardless of who wins the first-period one. Therefore, the highest price that allows firm 1 to capture the market in period one is $\widetilde{P}^{1}=u-\Delta+\left(\phi^{b}-\phi^{1}\right)$. In this case, firm 1's overall profit is given by

$$
\widetilde{\Pi}_{1}=\widetilde{\Pi}_{1}^{1}+\widetilde{\Pi}_{1}^{2}=(u-\Delta)+\left(\phi^{b}-\phi^{1}\right)+\delta\left[u-\Delta+\left(\phi^{b}-\phi^{2}\right)\right]
$$


In contrast, if firm 1 gives up the market in period 1 , its profit becomes $\widetilde{\Pi}_{1}=\widetilde{\Pi}_{1}^{1}+\widetilde{\Pi}_{1}^{2}=$ $0+\delta\left(u-\Delta-\left(\phi^{b}-\phi^{2}\right)\right)$. Thus, firm 1 chooses the first option. Therefore, tying can be profitable if the following condition holds

$$
\widetilde{\Pi}_{1}=(u-\Delta)+\left(\phi^{b}-\phi^{1}\right)+\delta\left(u-\Delta+\left(\phi^{b}-\phi^{2}\right)\right)>(1+\delta) u=\Pi_{1},
$$

that is,

$$
\left(\phi^{b}-\phi^{1}\right)+\delta\left(\phi^{b}-\phi^{2}\right)>(1+\delta) \Delta .
$$

If $N^{1}=N^{2}$ with $\phi^{1}=\phi^{2}$, this condition simplifies to

$$
\phi^{b}-\phi^{2}>\Delta \text {. }
$$

Carlton and Waldman (2002) develop a related model of tying for complementary products in the presence of network effects. However, in their model tying is strategically used to preserve monopoly power rather than extend monopoly power to another market. In their model, for some parameter constellations the monopolist need not actually tie its products and can achieve the same goal with a virtual tie by charging a "high" price for the tying product and a "low" price for the tied product because they consider complementary products. They point out that a real tie is needed when the non-negativity constraint for the tied product is binding but do not systematically explore implications of the nonnegativity constraint as we do in the current paper. ${ }^{28}$

\subsubsection{Tying in Markets with Switching Costs}

Market $A$ is the same as in the baseline model, monopolized by firm 1 with consumers having valuation of $u$ for the product. Market $B$ is one-sided but characterized with a switching costs of $s$ (Klemperer, 1990). We consider a two-period model with a discount factor of $\delta$. Once again, firms' production costs are zero in all markets.

In the absence of tying, firm 1 charges a price of $p_{1}^{A}=u$ in its monopolized market $A$. In market $B$, we apply backward induction to derive the equilibrium. Suppose that firm 1 has captured market $B$ in the first period. In the second period, consumers need to pay a switching cost of $s$ to buy from firm 2. To illustrate the idea in the simplest

\footnotetext{
${ }^{28}$ They also provide a model with network effects in which strategic tying is used to extend monopoly power to the newly emerging market. However, their logic applies only when the tying and the tied products are complementary and the new product in the emerging market is a perfect substitute for a system consisting of the tying and the tied products.
} 
manner, let us assume that $s>\Delta=v_{2}-v_{1}>0$ and $(s-\Delta)<u$. In this case, firm 1 will be able to maintain its market dominance with a price of $(s-\Delta)$. If firm 2 has captured market $\mathrm{B}$ in the first period, it can maintain the market at a price of $(s+\Delta)$.

Now consider market competition in the first period. For analytical simplicity, we assume myopic consumers. Firm 1 is willing to charge a price which is $-(s-\Delta)<0$. However, the non-negative price constraint limits its price at zero. Given this, firm 2 is able to sell at a price of $\Delta$ in the first period. As a result, each firm's overall profits are given by

$$
\begin{aligned}
& \Pi_{1}=(1+\delta) u \\
& \pi_{2}^{B}=\Delta+\delta(s+\Delta)
\end{aligned}
$$

Now suppose that firm 1 ties its monopolized product $A$ with product $B 1$. Consider a subgame in which all consumers bought the bundle. Let $\widetilde{P}^{2}$ and $\widetilde{p}_{2}^{2}$ denote the bundle price and firm 2 's price for product $B 2$ in period 2 under tying. Then, firm 1 will be able to sell its bundled products if

$$
u+v_{1}-\widetilde{P}^{2} \geq v_{2}-\widetilde{p}_{2}^{2}-s .
$$

Since firm 2 will be willing to set the price as low as its marginal cost, which is zero, the maximum price firm 1 can charge for its bundle in order to make sales is given by $\widetilde{P}^{2}=u-\Delta+s$. Under tying, firm 1's profits in the second period are given by

$$
\widetilde{\Pi}_{1}^{2}=u-\Delta+s>u
$$

If consumers bought from firm 2 in period 1, the maximum price firm 1 can charge for its bundle in order to make sales is given by $\widetilde{P}^{2}=u-\Delta-s$. Firm 1's profits in period 2 in this subgame is given by

$$
\widetilde{\Pi}_{1}^{2}=u-\Delta-s .
$$

Consider competition in period 1 under tying. If firm 1 decides to capture the market in period 1 , its price needs to satisfy

$$
u+v_{1}-\widetilde{P}^{1} \geq v_{2}-\widetilde{p}_{2}^{1}
$$

This implies that the highest price firm 1 can charge in period 1 and still capture the 
market is given by $\widetilde{P}^{1}=u-\Delta$. In this case, firm 1's overall profit is given by

$$
\widetilde{\Pi}_{1}=\widetilde{\Pi}_{1}^{1}+\widetilde{\Pi}_{1}^{2}=(u-\Delta)+\delta(u-\Delta+s)
$$

In contrast, if firm 1 gives up the market in period 1 , its profit becomes $\widetilde{\Pi}_{1}=\widetilde{\Pi}_{1}^{1}+\widetilde{\Pi}_{1}^{2}=$ $0+\delta(u-\Delta-s)$. Thus, firm 1 chooses the first option. Therefore, tying can be profitable if the following condition holds

$$
\widetilde{\Pi}_{1}=(u-\Delta)+\delta(u-\Delta+s)>(1+\delta) u=\Pi_{1},
$$

which can be written as

$$
s>\frac{1+\delta}{\delta} \Delta .
$$

\subsection{Duality Model with the Non-Positive Price Constraint in the Tying Good Market: Application to the Google Android Case}

We have developed a leverage theory of tying in two-sided markets with the non-negative price constraint in the tied good market, motivated by the Google Android case . However, actual antitrust cases are fact-intensive and our model does not perfectly fit with the current Google case in one important aspect. More specifically, the assumption of non-negative prices is more appropriate for consumers, but in reality mobile phone manufacturers make decisions on which apps to pre-install and app developers can make payments to OEMs to have their apps to be pre-installed, which effectively constitutes a negative price for consumers if the payments to OEMs are passed along to consumers.

To address this issue, we develop a dual model with the non-positive constraint in the tying good market, as opposed to the non-negative price constraint in the tied good market. For the sake of concreteness, consider YouTube or Google Play as the (monopolized) tying good (as there are no effective competitors) and Google search as the tied good (for which there are some potential competitors). ${ }^{29}$ Suppose that for some reason (outside of the model) Google is not charging or unable to charge any positive price to consumers or OEMs for YouTube or Google Play.

In reality, consumers can use these applications for free and as their pre-installation by OEMs simply facilitates consumers' usage, it seems hard for Google to charge OEMs for the pre-installation. To explain why Google offers such killer applications for free, we can

\footnotetext{
${ }^{29}$ See Edelman and Geradin (2016) and the EC's press release available at http://europa.eu/rapid/press-release_MEMO-16-1484_en.htm.
} 
think of the following microfoundation based on reference-dependent preferences. ${ }^{30}$ When these apps were first introduced, they needed to be offered for free for strategic reasons such as market penetration and building an installed base of consumers. Even when they have established a dominant position with insurmountable lead over competitors, they may not be able to charge a positive price if consumers are accustomed to free app and balk at paying any positive price. In other words, consumers' loss aversion with the zero reference price creates a non-positive price constraint for Google.

This implies that Google has a "surplus slack" in the tying good market (due to the non-positive price constraint), which can be leveraged to the tied good market via bundling. Note that in the Chicago school critique of the leverage theory, the tying firm is extracting all surplus in the tying good market in the absence of bundling, which renders bundling unprofitable. If the tying firm is not extracting all surplus in the tying good market (as in the case of YouTube), we can restore incentives to tie.

To illustrate this idea, we consider the same model as in section 2.1, but we allow negative prices in the tied good market whereas there is non-positive price constraint in the tying good market. This implies that the tying firm can use the surplus of $u$ in competition for the tied good because its price for the tying good is constrained to be zero $\left(p_{1}^{A}=0\right)$. Without tying, the only source for firm 1's profit in market $A$ is from the advertiser side with $\pi_{1}^{A}=\alpha$. In market $B$, firm 1 is willing to set its price below its marginal cost on the consumer side up to $\beta$ with $p_{1}^{B}=-\beta$. In response, firm 2 charges a price of $p_{2}^{B}=-\beta+\Delta$ with a profit of $\pi_{2}^{B}=\Delta$.

Now suppose that firm 1 ties its monopolized product with product $B$ on the consumer side. Then, firm 1 is able to sell its bundled products only if

$$
u+v_{1}-\widetilde{P} \geq v_{2}-\widetilde{p}_{2}
$$

As firm 2 is willing to charge a price as low as $\widetilde{p}_{2}=-\beta$, the maximum bundle price that enables the tying firm to make sales is $\widetilde{P}=u-\Delta-\beta$. The tying firm's profit under bundling is given by $\widetilde{\Pi}_{1}=(u-\Delta-\beta)+(\alpha+\beta)=u-\Delta+\alpha$. Thus, if $u>\Delta$, tying is profitable, restoring incentives to tie.

\footnotetext{
${ }^{30}$ See, for instance, Koszegi and Rabin (2006) for reference-dependent preferences.
} 


\section{Heterogenous Consumers in the Tying Market}

In this section, we consider heterogeneous consumers in market $A$. To derive a closed-form solution, we assume that $u$ is uniformly distributed on $[0,1]$, which yields a linear demand function in market $A .{ }^{31}$ Market $\mathrm{B}$ is modeled as in the baseline model.

In the absence of tying, the two platform markets can be analyzed independently. In market $B$, the analysis is the same as in Section 2 . In market $A$, firm 1 chooses $p$ on the consumer side to maximize

$$
\max _{p}(p+\alpha)(1-p)
$$

Under the non-negativity constraint on price, the monopolistic platform's optimal price is given by

$$
p^{m}=\left\{\begin{array}{c}
\frac{1-\alpha}{2} \text { if } \alpha<1 ; \\
0 \text { otherwise }
\end{array}\right.
$$

The optimal price in the consumer side decreases with the importance of advertising revenue $(\alpha) .{ }^{32}$

Therefore, without tying, each firm's profit is given by

$$
\begin{aligned}
& \Pi_{1}=\pi^{m}=\left\{\begin{array}{c}
\frac{(1+\alpha)^{2}}{4} \text { if } \alpha<1 \\
\alpha \text { otherwise }
\end{array} ;\right. \\
& \pi_{2}=\Delta+\beta .
\end{aligned}
$$

We assume $\Delta<1 / 2$. Under the assumption, if both firms charge zero price under tying, firm 1's market share is larger than a half. Hence, this assumption implies that firm 1 has a significant ability to leverage its monopoly power in market $B$.

\subsection{Equilibrium under Tying}

Now suppose that firm 1 engages in tying on the consumer side. Consumers have two choices: they can buy a bundled product/service from firm 1 or buy only product/service $B$ from firm 2 . Let $\widetilde{P}$ and $\widetilde{p}_{2}$ be the bundle price by firm 1 and product $B$ price by firm

\footnotetext{
${ }^{31}$ The uniform distribution assumption is made for simplicity to derive a closed-form solution in our model. We can derive qualitatively similar results with a more general distribution of $u$.

${ }^{32}$ We can assume a more general distribution of $u$. If $u$ is distributed according to cdf $G($.$) , the$ maximization problem becomes $\max (p+\alpha)[1-G(p)]$ and the optimal price is characterized by $p^{m}=$ $\frac{1-G\left(p^{m}\right)}{g\left(p^{m}\right)}-\alpha$. With a monotone hazard rate condition, it can be shown that $p^{m}(\alpha)$ is decreasing in $\alpha$.
} 
2 , respectively. The consumer type $u^{*}$ who is indifferent between the bundled offering and firm 2's single product offering satisfies the following condition:

$$
\left(u^{*}+v_{1}\right)-\widetilde{P}=v_{2}-\widetilde{p}_{2},
$$

which is equivalent to

$$
u^{*}=\left(\widetilde{P}-\widetilde{p}_{2}\right)+\Delta .
$$

As the bundle will be bought by consumers with valuations $u \geq u^{*}$, the demand for the bundle is given by

$$
D\left(\widetilde{P}, \widetilde{p}_{2}\right)=\left\{\begin{array}{cl}
1-u^{*}=1-\left[\left(\widetilde{P}-\widetilde{p}_{2}\right)+\Delta\right] & \text { if } 0 \leq\left(\widetilde{P}-\widetilde{p}_{2}\right)+\Delta \leq 1 \\
1 & \text { if } 0 \leq \widetilde{P}<\widetilde{p}_{2}-\Delta \\
0 & \text { if } \widetilde{P}>1+\widetilde{p}_{2}-\Delta
\end{array}\right.
$$

Firm 2's demand is $1-D\left(\widetilde{P}, \widetilde{p}_{2}\right)$. We have:

Lemma 1. Under tying

(i) Firm 1's best response is given by

$$
B R_{1}\left(\widetilde{p}_{2}\right)=\left\{\begin{array}{cc}
\frac{(1-\Delta)-(\alpha+\beta)+\widetilde{p}_{2}}{2} & \text { for } \Delta+[1-(\alpha+\beta)] \geq \widetilde{p}_{2}>\Delta-[1-(\alpha+\beta)] ; \\
\max \left[0, \widetilde{p}_{2}-\Delta\right] & \text { otherwise }
\end{array}\right.
$$

(ii) Firm 2's best response is given by

$$
B R_{2}(\widetilde{P})=\max \left[\frac{(\Delta-\beta)+\widetilde{P}}{2}, 0\right] .
$$

Therefore, we have to distinguish four cases depending on whether or not $1-\Delta>\alpha+\beta$ and/or $\Delta>\beta$. Let $\left(\widetilde{P}^{\circ}, \widetilde{p}_{2}{ }^{\circ}\right)$ be the solution of

$$
\begin{aligned}
\widetilde{P} & =\frac{(1-\Delta)-(\alpha+\beta)+\widetilde{p}_{2}}{2} \\
\widetilde{p}_{2} & =\frac{(\Delta-\beta)+\widetilde{P}}{2} .
\end{aligned}
$$


That is,

$$
\begin{aligned}
\widetilde{P}^{\circ} & =-\beta+\frac{2(1-\alpha)-\Delta}{3} ; \\
\widetilde{p}_{2}^{\circ} & =-\beta+\frac{1-\alpha+\Delta}{3} .
\end{aligned}
$$

Then, depending on the relative magnitudes of two-sidedness parameters ( $\alpha$ and $\beta$ ) and vertical differentiation parameter $\Delta$, we have the following four cases for equilibrium prices under tying.

Case 1 (Both $\alpha$ and $\beta$ Small): $1-\Delta>\alpha+\beta$ and $\Delta>\beta$.

In this case, the non-negative price constraints are not binding and we have $\widetilde{P}^{*}=$ $\widetilde{P}^{\circ}(>0)$ and $\widetilde{p}_{2}^{*}=p^{\circ}(>0)$.

Case 2 (Both $\alpha$ and $\beta$ Large): $1-\Delta<\alpha+\beta$ and $\Delta<\beta$.

$$
\widetilde{P}^{*}=0, \widetilde{p}_{2}^{*}=0 \text {. }
$$

Case 3 (Small $\alpha$ and Large $\beta$ ): $1-\Delta>\alpha+\beta$ and $\Delta<\beta$.

In this case, it can be easily shown that $\widetilde{P}^{\circ}>\widetilde{p}_{2}{ }^{\circ}$. Thus, the non-negative price constraint is binding first for the rival firm's price under tying. We then have the following result.

(i) If $\beta<\frac{(1-\alpha)+\Delta}{3}$,

$$
\widetilde{P}^{*}=\widetilde{P}^{\circ}>0, \widetilde{p}_{2}^{*}=\widetilde{p}_{2}^{\circ}>0 .
$$

(ii) If $\beta>\frac{(1-\alpha)+\Delta}{3}$,

$$
\widetilde{P}^{*}=B R_{1}(0)=\frac{(1-\Delta)-(\alpha+\beta)}{2}, \widetilde{p}_{2}^{*}=0 .
$$

Case 4 (Large $\alpha$ and Small $\beta$ ): $1-\Delta<\alpha+\beta$ and $\Delta>\beta$.

This is the opposite of case 3 and the non-negative price constraint is binding first for the tying firm as $\widetilde{P}^{\circ}<\widetilde{p}_{2}{ }^{\circ}$. We have the following result.

(i) If $\beta<\frac{2(1-\alpha)-\Delta}{3}$,

$$
\widetilde{P}^{*}=\widetilde{P}^{\circ}>0, \widetilde{p}_{2}^{*}=\widetilde{p}_{2}^{\circ}>0 .
$$

(ii) If $\beta>\frac{2(1-\alpha)-\Delta}{3}$, 


$$
\widetilde{P}^{*}=0, \widetilde{p}_{2}^{*}=B R_{2}(0)=\frac{\Delta-\beta}{2} .
$$

The equilibrium price configurations under tying are summarized in Figure 1.

\subsection{Incentives to Tie in Two-Sided Markets}

We now analyze the monopolistic firm's incentives to tie for each price configuration regime.

- Case of $\widetilde{P}^{*}=0$ and $\widetilde{p}_{2}^{*}=0$

This case corresponds to a situation in which both firms' non-negative price constraints are binding under tying because both $\alpha$ and $\beta$ are relatively large compared to $\Delta$ (i.e., when $1-\Delta<\alpha+\beta$ and $\Delta<\beta$ ). With these prices, each firm's market demand under tying is given by

$$
\widetilde{D}_{1}=1-\Delta \text { and } \widetilde{d}_{2}=\Delta .
$$

Each firm's corresponding profit under tying is given by

$$
\begin{gathered}
\widetilde{\Pi}_{1}=(1-\Delta)(\alpha+\beta) ; \\
\widetilde{\pi}_{2}=\Delta \beta .
\end{gathered}
$$

Profit comparisons lead to:

Lemma 2. Consider the case when the equilibrium prices under tying are given by $\widetilde{P}^{*}=$ $0, \widetilde{p}_{2}^{*}=0$ (i.e., $\alpha+\beta>1-\Delta$ and $\beta>\Delta$ ).

(i) Tying unambiguously reduces the rival firm's profit.

(ii) Firm 1's incentive to tie increases with $\beta$ and decreases with $\alpha$. More precisely, tying is always profitable for $\alpha<(1-2 \Delta)$ and increases firm 1's profit if $\beta>\frac{(1-\alpha)^{2}+4 \alpha \Delta}{4(1-\Delta)}$ for $(1-2 \Delta)<\alpha<1$ and if $\frac{\beta}{\alpha}>\frac{\Delta}{1-\Delta}$ for $\alpha \geq 1$.

Tying reduces firm 2's profit by reducing its market share and its price. Firm 1's incentive to tie increases with $\beta$ since $\widetilde{\Pi}_{1}$ increases with $\beta$ but firm 1's profit without tying does not depend on $\beta$. This is consistent with the finding from the baseline model. In addition, Lemma 2(ii) shows that firm 1's incentive to tie decreases with $\alpha$ for given $\beta$. This is very clear when $\alpha>1$. Then, in market $A$, tying generates a loss of $\Delta \alpha$ since 


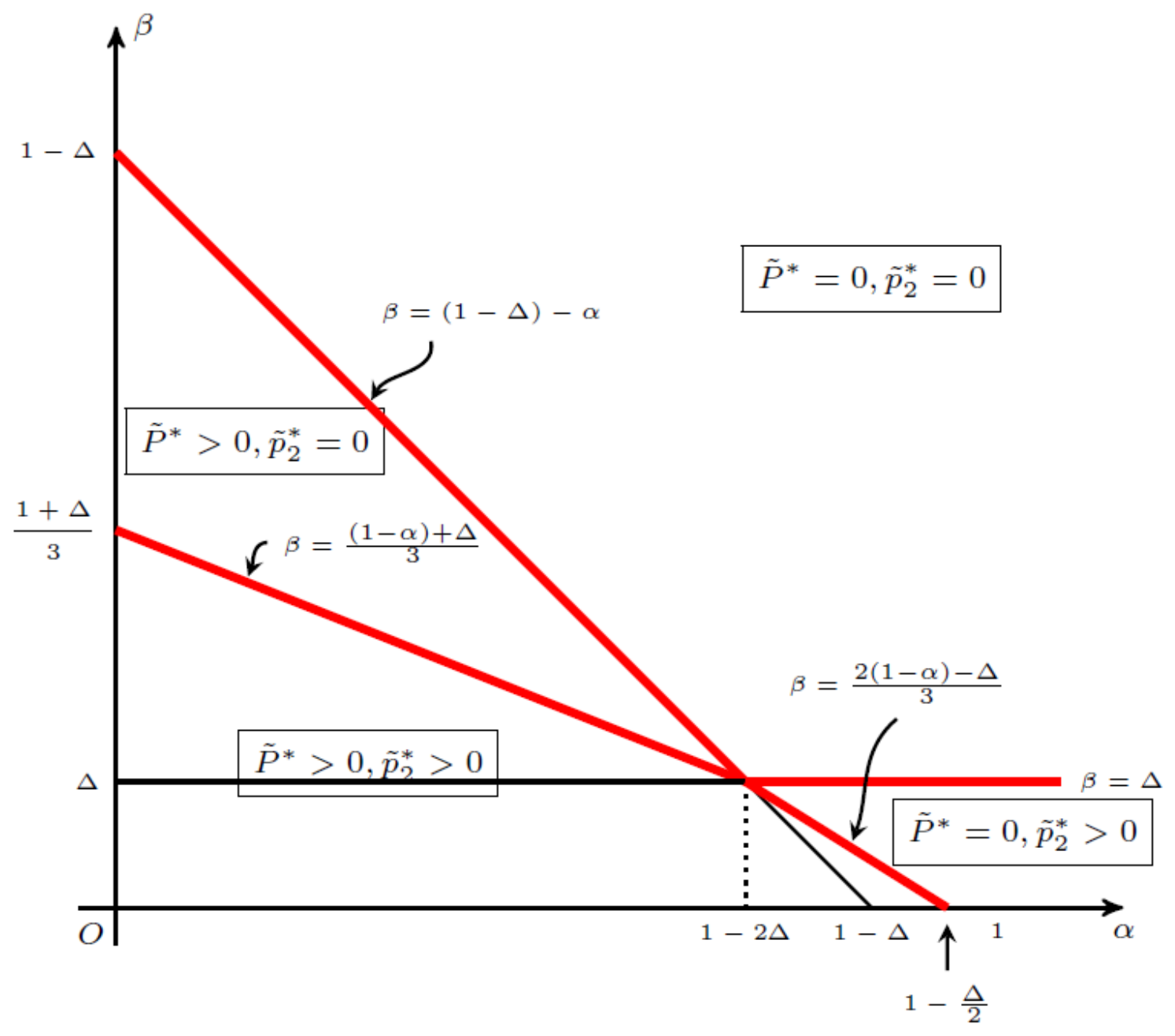

Figure 1: Equilibrium Price Configurations under Tying 
consumers with low valuations for the monopoly product buy firm 2's product instead of the bundle.

- $\widetilde{P}^{*}>0, \widetilde{p}_{2}^{*}=0$

This price regime arises when both $\alpha<1-2 \Delta$ and $1-\Delta-\alpha>\beta>(1-\alpha+\Delta) / 3$ hold. The latter condition implies $\beta>\Delta$. Essentially, market $A$ is close to being one-sided while market $B$ is quite two-sided. This case is fundamentally the same as the baseline model and we have:

Lemma 3. When the equilibrium prices under tying are given by $\widetilde{P}^{*}>0$ and $\widetilde{p}_{2}^{*}=0$ (i.e., when both $\alpha<1-2 \Delta$ and $1-\Delta-\alpha>\beta>(1-\alpha+\Delta) / 3$ hold $)$, tying is always profitable for firm 1 whereas tying always reduces the rival firm's profit.

- Case of $\widetilde{P}^{*}>0$ and $\widetilde{p}_{2}^{*}>0$

This price regime arises under tying when both $\alpha$ and $\beta$ are relatively small compared to $\Delta$. More precisely, the following condition needs to hold:

$$
\begin{aligned}
& \beta<\frac{(1-\alpha)+\Delta}{3} \text { if } \alpha<1-2 \Delta \\
& \beta<\frac{2(1-\alpha)-\Delta}{3} \text { if } \alpha>1-2 \Delta .
\end{aligned}
$$

In this case, the non-negative price constraint is binding for neither firm as $\widetilde{P}^{*}=\widetilde{P}^{\circ}>$ $0, \widetilde{p}_{2}^{*}=\widetilde{p}_{2}{ }^{\circ}>0$.

Firm 1 and firm 2's demands are respectively given by

$$
\widetilde{D}_{1}=\frac{2+\alpha-\Delta}{3}, \widetilde{d}_{2}=\frac{(1-\alpha)+\Delta}{3} .
$$

The corresponding profits are given by

$$
\widetilde{\Pi}_{1}=\left[\frac{2+\alpha-\Delta}{3}\right]^{2}, \widetilde{\pi}_{2}=\left[\frac{(1-\alpha)+\Delta}{3}\right]^{2} .
$$

Since each firm reduces its price by $\beta, \beta$ is competed away and therefore both firms' profits under tying are independent of $\beta$. Note that the highest $\alpha$ that satisfies the conditions above for this price regime is $\alpha=1-\frac{\Delta}{2}<1$. Hence, firm 1's profit under no tying is $\Pi_{1}=\frac{(1+\alpha)^{2}}{4}$. We have $\widetilde{\Pi}_{1}>\Pi_{1}$ if and only if $\alpha<1-2 \Delta$. The comparison of the 
rival firm's profits shows that $\tilde{\pi}_{2}>\pi_{2}$ if $\beta<\left[\frac{(1-\alpha)+\Delta}{3}\right]^{2}-\Delta$. We thus have the following lemma.

Lemma 4. Consider the case when the equilibrium prices under tying are given by $\widetilde{P}^{*}>0$ and $\widetilde{p}_{2}^{*}>0$ (i.e., either $\beta<\frac{(1-\alpha)+\Delta}{3}$ and $\alpha<1-2 \Delta$ hold or $\beta<\frac{2(1-\alpha)-\Delta}{3}$ and $\alpha>1-2 \Delta$ hold).

(i) Tying is profitable for firm 1 if and only if $\alpha<1-2 \Delta$.

(ii) Tying also increases the rival firm's profits if and only if $\beta<\left[\frac{(1-\alpha)+\Delta}{3}\right]^{2}-\Delta$.

(iii) When $\alpha=\beta=0$, tying is profitable for both firms if $\Delta \lesssim 0.14590$.

Note that the possibility of tying to relax competition and increase both firms' profits can arise only when $\Delta \leq \frac{7-3 \sqrt{5}}{2} \simeq 0.14590$. Lemma 4 implies that when $\Delta$ is small, tying increases both firms' profits if both $\alpha$ and $\beta$ are close to zero (i.e., when both markets are essentially one-sided). For instance, when $\alpha=\beta=0$, Lemma 4(iii) shows that tying increases both firms' profits if and only if $\Delta \lesssim 0.14590$. This result replicates the insight provided by Carbajo et al. (1990) for the case of standard one-sided markets. When firms compete in prices, tying/bundling provides a mechanism to differentiate products. High valuation consumers for the tying product buy the bundled product whereas low valuation consumers just buy the stand-alone product provided by the rival firm in the tied good market. This relaxes competition in the tied good market. This intuition comes out clearly if we consider an extreme case of $\Delta=0$. In this case, the tied good product is homogeneous and the equilibrium price will be driven down to zero (or more generally to $\mathrm{MC}$ if $\mathrm{MC}>0$ ) and both firms receive zero profits in market $B$ in the absence of tying. With tying, both firms can increase profits by segmenting the market.

- Case of $\widetilde{P}^{*}=0$ and $\widetilde{p}_{2}^{*}>0$

This price regime arises when the following condition holds.

$$
\frac{2(1-\alpha)-\Delta}{3}<\beta<\Delta .
$$

The parameter restriction of $\beta<\Delta$ implies that market $B$ is not two-sided enough since the assumption in the baseline model $\beta>\Delta$ is violated. Moreover, the condition implies $1-2 \Delta<\alpha$ (i.e., market $A$ can be quite two-sided). Therefore, tying is not profitable for firm 1 . Tying reduces firm 2's profit as well by reducing its price and its market share. 
Lemma 5. When the equilibrium prices under tying are given by $\widetilde{P}^{*}=0$ and $\widetilde{p}_{2}^{*}>0$ (i.e., when $\frac{2(1-\alpha)-\Delta}{3}<\beta<\Delta$ holds), tying reduces both firms' profits.

For $\alpha$ large and $\beta$ small, tying makes both firms more aggressive since the prices under tying are lower than the prices without tying. It thereby reduces both firms' profits, which is reminiscent of the finding of Whinston (1990).

All cases taken together, we can summarize our analysis so far in the following proposition.

Proposition 4. Consider the model in which consumers are heterogenous in terms of their valuations for the monopoly product. Assume $1 / 2>\Delta$.

(i) Firm 1's incentive to tie increases with $\beta$ and decreases with $\alpha$. Specifically, firm 1 has incentives to tie if $\alpha<(1-2 \Delta)$. For $\alpha \in(1-2 \Delta, 1)$, tying is profitable if $\beta>$ $\frac{(1-\alpha)^{2}+4 \alpha \Delta}{4(1-\Delta)}$. For $\alpha>1$, tying is profitable if $\frac{\beta}{\alpha}>\frac{\Delta}{1-\Delta}$.

(ii) Tying is more likely to reduce firm 2's profit as $\alpha$ increases and as $\beta$ increases. Specifically, tying reduces firm 2's profit unless $\beta<\left[\frac{(1-\alpha)+\Delta}{3}\right]^{2}-\Delta$ and $\alpha<(1-2 \Delta)$.

The area in which tying is not profitable for firm 1 is represented by the shaded area in the right bottom corner of Figure 2. In all other areas tying is profitable. For the rival firm, the area in which tying is profitable is represented as the triangle area near the origin in Figure 2. In all other areas tying reduces the rival firm's profit.

We make two remarks from our analysis. First, tying is profitable and reduces the rival's profit if $\beta$ in the tied good market is sufficiently large. As a result, our leverage mechanism does not have any credibility issue, in sharp contrast to the tying literature in one-sided markets (Whinston (1990) and Nalebuff (2004)). More specifically, our mechanism does require neither technical tying as a commitment device as in Whinston (1990) nor the controversial assumption that the tying firm is a Stackelberg leader in setting prices as in Nalebuff (2004). The use of contractual tying, even if it can be easily undone, is sufficient for credible leverage. Second, tying reduces both firms' profits if $\alpha$ in the tying good market is sufficiently large (relative to $\beta$ ). In the next section, we will investigate how this second result is affected by the presence of inter-group network effects.

\subsection{Welfare Analysis}

The welfare effects of tying in our model depend on whether or not the monopoly price in market $A$ is already zero (i.e., $\alpha \geq 1$ ) in the absence of tying. 


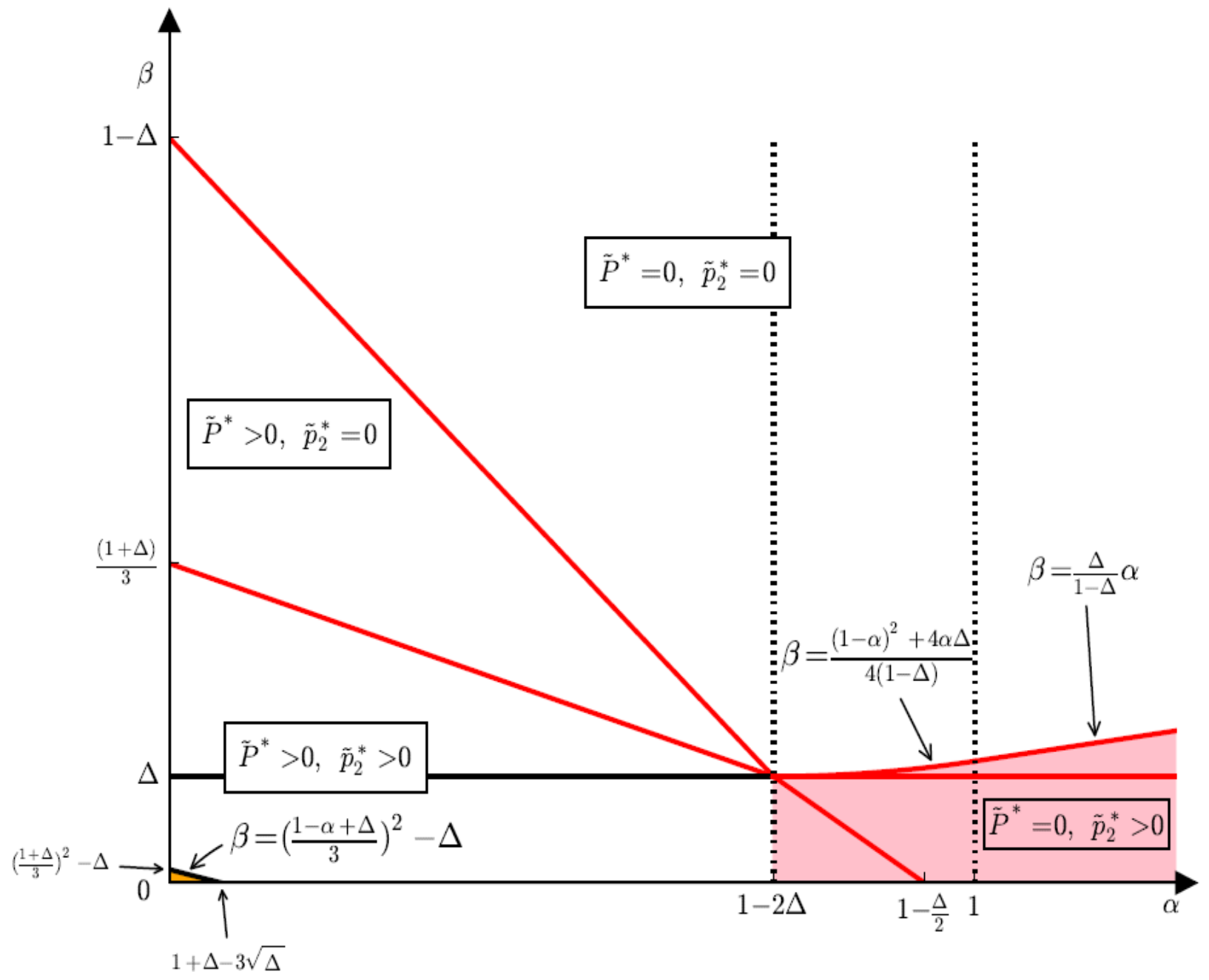

Figure 2: Incentives to Tie in Two-Sided Markets 
Case 1. (Full Market Coverage Case without Tying) $\alpha \geq 1$

For $\alpha \geq 1$, the price in market $A$ is zero and all consumers enjoy the service without tying, which is an efficient outcome. The equilibrium in market $B$ is also efficient without tying because all consumers use the more efficient service provided by firm 2 . Therefore, tying can only reduce social welfare. From Proposition 4 , we know that for $\alpha \geq 1$, firm 1 has incentives to engage in tying only for the parameter values such that the post-tying equilibrium prices are characterized by $\widetilde{P}^{*}=0, \widetilde{p}_{2}^{*}=0$ (see Figure 2 ). In this case, there are two sources of inefficiencies. First, any consumer whose valuation in market $A$ is less than $\Delta$ purchases from firm 2 and consumes only product $B$. Second, consumers whose valuation in market $A$ is more than $\Delta$ inefficiently switch from firm 2 's more efficient product to the bundled product. Note that consumer surplus increases in this case due to a decrease in the price of firm 2's product from $\Delta$ to zero. Consumers whose valuation in market $A$ is more than $\Delta(u>\Delta)$ are indifferent between the two regimes, but low type consumers in market $A$ (whose $u<\Delta$ ) gain with tying because their utility is $v_{2}$ with tying while it was $u+v_{1}$ without tying.

Case 2. (Partial Market Coverage Case without Tying) $\alpha<1$

When $\alpha<1$, the price in market $A$ is positive without tying and the market outcome is inefficient whereas the market outcome in $B$ is efficient. As in the previous case, tying can introduce inefficiency in market $B$ when firm 1 inefficiently serves consumers with a bundled product, but there can be a positive market expansion effect in market $\mathrm{A}$ as the bundle price is reduced. As a result, social welfare can be ambiguous. However, for social welfare to increase with tying a necessary condition is that market $A$ expands with tying. The next lemma derives the condition under which market $A$ expands with tying.

Lemma 6. Market $A$ expands with tying if and only if $\alpha<1-2 \Delta$.

The immediate corollary of lemma 6 is that tying decreases social welfare if $\alpha>1-2 \Delta$.

Now let us consider the case where $\alpha<1-2 \Delta$ and hence market $A$ expands with tying. More generally, the social welfare change with tying $(\Delta W)$ in this case can be written as

$$
\Delta W=\underbrace{\underbrace{\frac{1-\alpha}{2}}_{1-\widetilde{D}_{1}}(u+\alpha) d u}_{\begin{array}{c}
\text { Welfare Gain in Market A } \\
\text { due to Market Expansion }
\end{array}}-\underbrace{\widetilde{D}_{1} \Delta}_{\text {Social Welfare Loss in Market B }},
$$


where $\widetilde{D}_{1}$ denotes the demand for the bundle after tying. After analyzing the welfare effects of tying depending on the equilibrium price configurations (see the proof of Proposition 5), we find that tying increases welfare for $\Delta$ small enough as in this case the welfare loss in market B is small.

Proposition 5. Tying is welfare-reducing if $\alpha>1-2 \Delta$ since market $A$ contracts and there is inefficient switching in market $B$. If $\alpha<1-2 \Delta$, market $A$ expands and tying can enhance welfare if $\Delta$ is sufficiently small since inefficiency associated with tying in market $B$ becomes arbitrary small as $\Delta \rightarrow 0$.

\section{Heterogenous consumers with intergroup network effects}

Up to now, we assumed two-sided markets in which the consumer side serves as a competitive bottleneck but did not derive any direct utilities (or disutilities) from the other side which can be considered as advertisers. This was to capture the advertising revenue-based business model of many Internet platform markets such as Google. In this section, we extend our analysis by explicitly considering intergroup network effects from the other side to consumers. For instance, we can interpret the other side as app producers or content providers. In the presence of network effects, consumers' choices can exhibit strategic complementarity and coordination plays an important role. In such a situation, tying can be used as a strategic instrument to help consumers coordinate and coalesce around the bundled product. We investigate how the presence of network effects affects the previous results on the relationship between the incentive to tie and $\alpha$ (and $\beta$ ).

For simplicity, we assume that the monopolistic platform market $A$ is the same as in Section 3 . We modify market $B$ as follows. Let $p_{i}^{c}$ be the price charged by platform $i$ on the consumer side in market $B$. Then, a consumer subscribing to platform $i$ in market $B$ derives a utility of

$$
v_{i}+\beta_{c} n_{i}^{a}-p_{i}^{c},
$$

where $\beta_{c}(>0)$ is a parameter representing intergroup network effects and $n_{i}^{a}$ is the measure of applications/content available at platform $i$. We assume $\Delta \equiv v_{2}-v_{1}>0$. On the application side, let $p_{i}^{a}$ be the price an application developer needs to pay to have access to consumers on platform $i$. An application developer's payoff from developing an application or creating content for platform $i$ is 


$$
\beta_{a} n_{i}^{c}-p_{i}^{a},
$$

where $\beta_{a}>0$ and $n_{i}^{c}$ is the measure of consumers on platform $i$. Marginal costs of serving consumers are once again assumed to be zero.

We consider the following sequential game.

1. Each firm (i.e., platform) sets the prices for consumers.

2. Consumers make purchase or subscription decisions

3. (After observing consumer choices at stage 2), each platform chooses the price for application developers

4. (After observing consumer choices at stage 2 and price choices at stage 3 ), application developers choose subscription decisions.

Stages 1 and 2 of this sequential game are identical to the games we studied in the previous sections. The main difference is that the advertising revenue per consumer in market $B$ was exogenously given in the previous sections whereas its equivalent is now endogenous: solving for Stages 3 and 4 allows us to compute the additional profit that a platform can obtain from the application side by attracting one more consumer. We assume that consumers single home while application developers can multihome. As usual, we analyze the game by using backward induction.

\subsection{Equilibrium on the Application Side}

Suppose that platform $i$ has $n_{c}^{i}$ measure of consumers on board. Let us study the game that starts at stage 4 .

In order to endogenously derive the number of applications available, we assume that each developer incurs a platform-specific fixed cost $f$. The fixed cost is distributed over the positive line with density equal to one. Given the heterogeneity in the fixed cost of development, an application developer will subscribe to platform $i$ if the following condition holds:

$$
\beta_{a} n_{i}^{c}-p_{i}^{a} \geq f
$$

Hence, given $n_{i}^{c}$ and $p_{i}^{a}$, the total measure of app developers who subscribe to platform $i$ is

$$
n_{i}^{a}\left(p_{i}^{a} ; n_{i}^{c}\right)=\beta_{a} n_{i}^{c}-p_{i}^{a} .
$$

Therefore, at stage 3 with $n_{i}^{a}$ determined in the previous stage, platform $i$ solves the 
following problem.

$$
\max _{p_{i}^{a}} p_{i}^{a} n_{i}^{a}\left(p_{i}^{a} ; n_{i}^{c}\right)=p_{i}^{a}\left(\beta_{a} n_{i}^{c}-p_{i}^{a}\right) .
$$

From the first-order condition for platform $i$ 's profit maximization, platform $i$ chooses

$$
p_{i}^{a}=\frac{\beta_{a} n_{i}^{c}}{2} .
$$

The measure of app developers who subscribe to platform $i$ also is given by $n_{i}^{a}=\frac{\beta_{a} n_{i}^{c}}{2}$ with a uniform distribution of $f$ with density one. As a result, given the number of consumers $n_{i}^{c}$, platform $i$ 's profit on the application side is

$$
\pi_{i}^{a}\left(n_{i}^{c}\right)=\left(\frac{\beta_{a} n_{i}^{c}}{2}\right)^{2}
$$

Note that this result does not depend on whether or not there is tying on the consumer side.

\subsection{Equilibrium on the Consumer Side}

We now analyze the effects of tying on the consumer side.

\subsubsection{No Tying}

Consider platform competition at stage 1 without tying. As we assume that all consumers are homogenous in market $B$, there can potentially be multiple equilibria for some price configurations due to positive intergroup network effects. In such cases, we assume that all identical consumers coordinate on the Pareto dominant equilibrium. ${ }^{33}$

Hence, if $p_{2}^{c}<p_{1}^{c}+\Delta$, all consumers coordinate on platform 2 as long as their individual rationality constraint is satisfied. Therefore, in equilibrium, we have $p_{1}^{c}=0, p_{2}^{c}=\Delta$ and all consumers join the more efficient platform 2, that is, $n_{1}^{c}=0$ and $n_{2}^{c}=1$. In this tipping equilibrium with $n_{2}^{c}=1$, firm 2 charges $p_{2}^{a}=\frac{\beta_{a} n_{2}^{c}}{2}=\frac{\beta_{a}}{2}$ on the application side and induces a measure of $n_{2}^{a}=\frac{\beta_{a}}{2}$ application developers to be on its platform. Thus, each consumer's payoff on platform 2 is

$$
v_{2}+\beta_{c} n_{2}^{a}-p_{2}^{c}=v_{2}+\beta_{c}\left(\frac{\beta_{a}}{2}\right)-\Delta=v_{1}+\eta,
$$

\footnotetext{
${ }^{33}$ This is a standard equilibrium selection criterion in the presence of multiple equilibria with network effects. See, for instance, Katz and Shaprio (1986) and Waldman (1993).
} 
where $\eta \equiv \frac{\beta_{c} \beta_{a}}{2}$ represents the network benefits in the tipping equilibrium. As in the analysis of the previous section, each consumer receives a surplus of $v_{1}$ due to platform competition on the consumer side. In addition, each consumer receives additional benefit of $\eta=\frac{\beta_{c} \beta_{a}}{2}$ from intergroup network effects.

\subsubsection{Tying}

Now consider the equilibrium in the tying regime in which platform 1 ties its monopolized product $A$ with another product in competitive two-sided market $B$, and charges $\widetilde{P}$ for the bundled product. We make the following assumption:

Assumption 1. (stability) $\beta_{c} \beta_{a}<1 \Leftrightarrow \eta<1 / 2$

Without this assumption, there cannot exist any interior equilibrium in which both platforms share the market in our two-sided market. This is because the feedback mechanism due to intergroup network effects magnifies any initial advantage of one platform and leads to exploding demands.

We further assume that $\Delta<1 / 2$ for tying to have a leverage effect in the tied good market. If $\Delta$ is too large (i.e., $\Delta>1 / 2$ ), the disadvantage of firm 1 vis-à-vis firm 2 is too large to overcome in the tied good market; tying has no leverage effect. Note that $\Delta<1 / 2$ along with the stability assumption implies that purchasing the bundle is the dominant strategy for the highest consumer type in market $A$ (whose $u=1$ ) if the bundle is offered for free. For this type of consumer, the valuation of product $A$ is so high that the bundled product is preferred even if all other consumers purchase stand-alone product $B 2$ and there are no application developers for $B 1$.

Therefore, in what follows, by using iterated elimination of dominated strategies, we study a cut-off equilibrium: we consider a $u^{*} \in[0,1]$ such that all consumers whose valuation from the monopoly product is higher than $u^{*}$ join platform 1 while all the rest join platform 2 , which implies that $n_{1}^{c}=1-u^{*}, n_{2}^{c}=u^{*}$ on the consumer side and $n_{1}^{a}=\frac{\beta_{a}}{2}\left(1-u^{*}\right), n_{2}^{a}=\frac{\beta_{a}}{2} u^{*}$.

Let $\widetilde{P}$ and $\widetilde{p}_{2}$ be the bundle price by firm 1 and firm 2 's price for product $B 2$ in the tying regime, respectively. In the (interior) cut-off equilibrium, $u^{*}$ is implicitly determined as follows:

$$
\left[u^{*}+v_{1}\right]+\eta\left(1-u^{*}\right)-\widetilde{P}=v_{2}+\eta u^{*}-\widetilde{p}_{2}
$$

The LHS of (3) represents type $u^{*}$ consumer's utility when he purchases the bundled product whereas the RHS of (3) represents type $u^{*}$ consumer's utility when he purchases 
only product $B$ supplied by firm 2 . The critical type $u^{*}$ is indifferent between these two options. Hence,

$$
n_{2}^{c}\left(\widetilde{P}, \widetilde{p}_{2}\right)=u^{*}= \begin{cases}\frac{\Delta+\widetilde{P}-\widetilde{p}_{2}-\eta}{\left(1-\beta_{c} \beta_{a}\right)}, & \text { if } \widetilde{P}>\widetilde{p}_{2}+\eta-\Delta ; \\ 0, & \text { if } \widetilde{P} \leq \widetilde{p}_{2}+\eta-\Delta .\end{cases}
$$

The expression for $n_{2}^{c}$ above reveals new effects of tying in the presence of intergroup network effects. If there are no network effects (i.e., $\beta_{c} \beta_{a}=0$ ), firm 2 can always guarantee a positive market share unless its price does not exceed the bundle price by $\Delta$. For instance, if firm 2 charges a price of zero, firm 2 will always have some positive market share $\left(n_{2}^{c}>0\right)$. However, because of the existence of network externalities (i.e., as the number of consumers who choose platform 1 increases, the applications available on that platform increases), tying can create an advantage for platform 1 if tying provides a mechanism for firm 1 to capture more consumers than firm 2 . As the network effects term $\left(\beta_{c} \beta_{a}\right)$ increases, firm 2's market share decreases down to zero and eventually tying leads to the foreclosure of firm 2 in the market. Note that $\frac{\partial n_{2}^{c}}{\partial \widetilde{P}}=\left|\frac{\partial n_{2}^{c}}{\partial \widetilde{p}_{2}}\right|=\frac{1}{1-\beta_{c} \beta_{a}}>1$ is a multiplier in the two-sided market. It shows that the demand changes more sensitively to price as $\beta_{c} \beta_{a}$ increases.

Consider the case where $n_{2}^{c}\left(\widetilde{P}, \widetilde{p}_{2}\right)>0$. Then, we can decompose the market share of the tying firm into two terms as follows:

$$
n_{1}^{c}\left(\widetilde{P}, \widetilde{p}_{2}\right)=1-n_{2}^{c}\left(\widetilde{P}, \widetilde{p}_{2}\right)=\underbrace{1-\left[\left(\widetilde{P}-\widetilde{p}_{2}\right)+\Delta\right]}_{\begin{array}{c}
\text { Demand in the Absence of } \\
\text { Intergroup Network Effects }
\end{array}}+\underbrace{\frac{\beta_{c} \beta_{a}}{\left(1-\beta_{c} \beta_{a}\right)}\left[\frac{1}{2}-\left[\left(\widetilde{P}-\widetilde{p}_{2}\right)+\Delta\right]\right]}_{\begin{array}{c}
\text { Induced Demand Due to } \\
\text { Intergroup Network Effects }
\end{array}},
$$

where $1-\left[\left(\widetilde{P}-\widetilde{p}_{2}\right)+\Delta\right]$ is a hypothetical demand for firm 1 in the absence of intergroup network effects (i.e., $\beta_{c} \beta_{a}=0$ ), which we have seen in Section 3 (see equation (2)).

In order to understand equilibrium pricing, it is useful to decipher the economic meaning of $\Psi \equiv 1-\beta_{c} \beta_{a}-\frac{\left(\beta_{a}\right)^{2}}{2}$. As firm 1's profit under tying is given by $\widetilde{\Pi}_{1}=$ $\left[\widetilde{P}+\alpha+\frac{\left(\beta_{a}\right)^{2} n_{1}^{c}}{4}\right] n_{1}^{c}$, its first-order condition for profit maximization is given by:

$$
\frac{\partial \widetilde{\Pi}_{1}}{\partial \widetilde{P}}=\frac{\partial n_{1}^{c}}{\partial \widetilde{P}}\left[\widetilde{P}+\alpha-n_{1}^{c} \Psi\right]=0
$$


where $\frac{\partial n_{1}^{c}}{\partial \widetilde{P}}=-\frac{1}{1-\beta_{c} \beta_{a}}$. We can rewrite the condition above in a modified Lerner index form:

$$
\frac{\widetilde{P}+\alpha}{\widetilde{P}}=\frac{n_{1}^{c} \Psi}{\widetilde{P}}
$$

If the tying firm did not take into account the effect of its bundle pricing decision on the profit from the application side, $\Psi$ would not contain the term $\frac{\left(\beta_{a}\right)^{2}}{2}$ and we would have $\Psi=1-\beta_{c} \beta_{a}$, which is equal to the inverse of $\left|\frac{\partial n_{1}^{c}}{\partial \widetilde{P}}\right|$. Therefore, we can state the first-order condition as the standard Lerner formula with the interpretation of $(-\alpha)$ as the opportunity cost of the bundle. $\Psi$ corrects the standard formula by taking into account the fact that an increase in market share increases the profit from the application market through the network effects. If this effect is large such that $\Psi \leq 0$, firm 1 finds it optimal to choose $\widetilde{P}=0$ for any $\alpha \geq 0$. The same remark applies to firm 2 . Therefore, $-\Psi$ can be considered a measure of degree of competition induced by intergroup network effects, which increases with the network effects and the profit per consumer from the app market.

We can have two types of equilibria: an interior equilibrium in which firm 1 and firm 2 share the market with $n_{2}^{c}>0$ and the tipping equilibrium in which the tying firm captures the whole market with $n_{2}^{c}=0 .{ }^{34}$ The following proposition characterizes the equilibrium conditions.

Proposition 6. We have a tipping equilibrium (with $n_{1}^{c}=1$ and $n_{2}^{c}=0$ ) if $\eta \geq \Delta$ and $\alpha \geq \widehat{\alpha} \equiv(\Delta-\eta)+\Psi$, where $\Psi=1-\beta_{c} \beta_{a}-\frac{\left(\beta_{a}\right)^{2}}{2}$. Otherwise, we have an interior equilibrium with both $n_{1}^{c}>0$ and $n_{2}^{c}>0$.

In the appendix, we not only prove the proposition above but also further characterize equilibrium prices in each type of equilibrium. Proposition 6 shows that if $\Delta>\eta$, that is, the quality advantage of firm 2 is sufficiently large compared to the strength of network effects, we always have an interior equilibrium. However, if the network effects are relatively stronger than the quality advantage of firm 2 (i.e., $\Delta<\eta$ ), tying can be a mechanism for firm 1 to leverage its market power in $A$ to $B$ and lead to foreclosure of the rival firm. Note that the condition for tipping is more likely to be satisfied as $\alpha$ increases. For instance, if $\alpha>1$, we always have a tipping equilibrium as long as $\Delta<\eta$.

\footnotetext{
${ }^{34}$ With the maintained assumption of $\Delta<1 / 2$ and the stability assumption, there is no tipping equilibrium in which firm 2 captures the whole market.
} 


\subsection{Incentives to Tie with Intergroup Network Effects}

We now analyze incentives to tie in the presence of intergroup network effects. Proposition 6 shows that when $\Delta \leq \eta$ holds, a tipping equilibrium is more likely as $\alpha$ increases. This is because a high $\alpha$ induces the monopolist to price more aggressively in the consumer market, providing more surplus to inframarginal consumers, which can be leveraged to attract all consumers in market $B$ through network effects (see the demand decomposition in (4)). If tipping occurs, firm 1 captures all advertising revenue in market A, which breaks the result obtained in the previous section that there exists a critical value of $\alpha^{*}$ such that tying is not profitable if $\alpha \geq \alpha^{*}$.

\subsubsection{Tipping Equilibrium}

As shown in Proposition 6, we have a tipping equilibrium if $\Delta \leq \eta$ and $\alpha \geq 1-\left[\left(\beta_{c} \beta_{a}+\right.\right.$ $\left.\left.\frac{\left(\beta_{a}\right)^{2}}{2}\right)+(\eta-\Delta)\right]$. In the tipping equilibrium, $p^{*}=0, P^{*}=\eta-\Delta$. Thus, firm 1's profit with tying is $\widetilde{\Pi}_{1}^{*}=\alpha+\left(\frac{\beta_{a}}{2}\right)^{2}+(\eta-\Delta)$ while its profit without tying is $\Pi_{1}^{*}=\max \left\{\frac{1}{4}(1+\alpha)^{2}, \alpha\right\}$. When $\alpha \geq 1$, firm 1 serves all consumers in the tying market regardless of tying. Therefore, tying is profitable as it increases the profit from the tying market from $\alpha$ to $\alpha+\eta-\Delta$ and generates the profit from the apps. By continuity, tying is profitable for $\alpha$ close to one and we have the following result.

Proposition 7. When the tipping equilibrium prevails under tying, firm 1 has incentives to tie if $\alpha>\alpha^{*} \equiv 1-\sqrt{\left(\beta_{a}\right)^{2}+4(\eta-\Delta)}$.

Proof. When $\alpha \geq 1$, firm 1's profit without tying is $\alpha$. Since $\frac{\beta_{c} \beta_{a}}{2} \geq \Delta$ in the tipping equilibrium, it immediately follows that tying is profitable when $\alpha \geq 1$. For $\alpha<1$, firm 1 's profit under tying is $\frac{1}{4}(1+\alpha)^{2}$. A simple comparison of firm 1's profits under each regime yields the result.

The proposition indicates that tying is more likely to be profitable for $\alpha$ high, $\beta_{c}$ high and $\beta_{a}$ high. Propositions 6 and 7, taken together, yield the following Corollary.

Corollary 1. If $\eta \geq \Delta$ and $\alpha>\max \left[\widehat{\alpha}, \alpha^{*}\right]$ (where $\max \left[\widehat{\alpha}, \alpha^{*}\right]<1$ ), firm 1 engages in tying and the resulting equilibrium is a tipping equilibrium in which firm 2 is foreclosed from the market.

We point out the difference the introduction of intergroup network effects creates with respect to the result in the previous section. In section 3 , for a given $\beta$, tying becomes 
unprofitable at some point as $\alpha$ increases. The reason is that without network effects, the rival firm can always induce some marginal consumers in market $A$ to buy product $B$ when tying takes place. As a result, tying entails greater loss as $\alpha$ increases. However, this effect can disappear in the model with intergroup network effects if tying induces a tipping equilibrium, which is more likely when $\alpha$ is high.

\subsubsection{Interior Equilibrium}

Due to the conflicting effects of $\alpha$, the effects of tying on the tying firm's profits can be subtle in the interior equilibrium. As explained earlier, a higher $\alpha$ induces the tying firm to price more aggressively in the consumer market, providing more surplus to inframarginal consumers of $A$, which can be used to compete against firm 2 in market $B$ when tying takes place. In the interior equilibrium, however, capturing a certain share of market $B$ comes at the expense of the share of market $A$, which can be very costly when $\alpha$ is very high. We thus can show that tying cannot be a profitable strategy if $\alpha$ is sufficiently large as in Section 3.

In the case of an interior equilibrium, let us focus on the case in which $\widetilde{P}^{*}=0$. This holds either if $\Psi<0$ and $\eta<\Delta$ (see Lemma 7(ii) in Appendix) or if $\Psi \geq 0$ but $n_{1}^{c *} \Psi$ is bounded above by $\alpha$ (i.e. (6) is satisfied) (see Lemma 9(i) in Appendix). In both cases, firm 1's market share under tying is independent of $\alpha$ and is given by

$$
n_{1}^{c *}=\left\{\begin{array}{c}
1-\frac{\Delta-\eta}{(1-\eta)} \text { if } \Psi<0 \\
1-\frac{\Delta-\eta}{\Psi+(1-\eta)} \text { if } \Psi \geq 0 .
\end{array}\right.
$$

Define the difference between firm 1's profit under tying and firm 1's profit without tying as follows

$$
\Delta \Pi(\alpha) \equiv\left\{\begin{array}{cc}
n_{1}^{c *}\left(\alpha+\frac{\left(\beta_{a}\right)^{2}}{4} n_{1}^{c *}\right)-\left(\frac{1+\alpha}{2}\right)^{2}, & \text { if } \alpha \in[0,1] ; \\
n_{1}^{c *}\left(\alpha+\frac{\left(\beta_{a}\right)^{2}}{4} n_{1}^{c *}\right)-\alpha, & \text { if } \alpha>1 .
\end{array}\right.
$$

Suppose that $n_{1}^{c *}$ is close enough to one that $\Delta \Pi(1)>0$. Note first that $\Delta \Pi(\alpha)$ is concave for $\alpha \in[0,1]$. For $\alpha>1$, as $\Delta \Pi(\alpha)$ linearly decreases, there exists $\bar{\alpha}=\frac{\left(\beta_{a}\right)^{2}}{4} n_{1}^{c *} /\left(1-n_{1}^{c *}\right)$ at which $\Delta \Pi(\bar{\alpha})=0$. We below distinguish the case of $\Delta \Pi(0) \geq 0$ from $\Delta \Pi(0)<0$. Suppose $\Delta \Pi(0) \geq 0$. Then, tying is strictly profitable for any $\alpha \in(0, \bar{\alpha})$. If $\Delta \Pi(0)<0$, there exists some $\underline{\alpha} \in(0,1)$ at which $\Delta \Pi(\underline{\alpha})=0$. Hence, tying is profitable for any $\alpha \in(\underline{\alpha}, \bar{\alpha})$. As $\bar{\alpha}$ tends to $\infty$ when $n_{1}^{c *}$ goes to one, the result obtained when $\Delta \Pi(0)<0$ extends the result on the incentive to tie in the tipping equilibrium, described in Proposition 7 , to an 
interior market share.

\subsection{Welfare Analysis}

We now analyze welfare implications of tying. First consider the case where tying leads to tipping. If $\alpha>1$, all consumers in market $\mathrm{A}$ were served before tying. There is thus no market expansion effect in this case. The only effect is that consumers switch from firm 2's product to firm 1's product, which is inferior. Thus, tying unambiguously reduces welfare in this case, with the welfare loss being $\Delta$. If $\alpha<1$, but tying induces tipping, there is a positive market expansion effect in market $A$. The welfare gain from this market expansion can be expressed as

$$
E=\int_{0}^{\frac{1-\alpha}{2}} u d u+\left(\frac{1-\alpha}{2}\right) \alpha=\frac{(1+3 \alpha)(1-\alpha)}{8}
$$

This welfare gain needs to be measured against the loss in welfare in market $B$, which is $\Delta$. Tying can be welfare reducing if $E<\Delta$. $E$ is highest at $1 / 6$ when $\alpha=1 / 3$. Therefore, a sufficient condition that tying reduces welfare is $\Delta>1 / 6$ if tying induces tipping towards the bundled product.

If tying does not lead to tipping, there is an additional type of welfare loss due to a fragmented market structure which does not fully exploit network benefits.

We can also analyze the effects of tying on consumer surplus. For instance, suppose that $\alpha>1$ and tying leads to tipping. If $\widetilde{P}^{*}=0$, consumers are indifferent between tying and no tying. However, if $\widetilde{P}^{*}>0$, consumers lose from tying. Without tying, each consumer enjoys $\frac{\left(\beta_{a}\right)^{2}}{2}$ of surplus from firm 2 in market $B$ because of price competition in market $B$. Tying removes the level playing field and allows the tying firm to extract the surplus from network effects.

\section{Concluding Remarks}

In this paper, we have developed a leverage theory of tying in two-sided markets. The basic premise of our theory is that the optimal pricing and competition strategies in a two-sided market often lead to below-cost pricing on one side of the market whose loss is often recouped on the other side. When the below-cost pricing is constrained by the non-negative price constraint, competition is relaxed and supra-competitive profits can be 
created. A monopolist in another market can extract this surplus via a tying arrangement which effectively allows the tying firm to engage in negative pricing. Furthermore, as the competing firm in the tied two-sided market is constrained by non-negative pricing, its response to tying cannot be so aggressive, which in turn makes tying even more profitable. We also demonstrated that this mechanism can also be applied to other market contexts such as dynamic competition with direct network effects and switching costs.

Our analysis has focused on the effects of tying on short-run price competition and their implications on consumer surplus and welfare. In our baseline model with homogenous consumers, for instance, tying is welfare-reducing because it induces inefficient switching to the inferior product of the tying firm in the tied market. Nonetheless, consumers are not worse off because they are compensated for the consumption of the inferior product by the tying firm. However, if we consider rival firms' incentives to develop new products in the tied market, we may find further harm in consumer welfare because more innovative products may not be introduced by the rival firms due to the lack of market access. However, we also point out that there could be many efficient reasons to engage in tying such as integration of different apps which enables the tying firm to provide better and seamless services to consumers. Antitrust investigations should weigh these potential efficiencies against the potential harm identified in this paper. 


\section{References}

[1] Amelio, Andrea and Bruno Jullien, "Tying and Freebie in Two-Sided Markets," International Journal of Industrial Organization, 2012, pp. 436-446.

[2] Armstrong, Mark, "Competition in Two-Sided Markets," Rand Journal of Economics, 2006, 37 (3), pp. 668-691.

[3] Armstrong, Mark and Julian Wright, "Two-Sided Markets, Competitive Bottlenecks and Exclusive Contracts," Economic Theory, 2007, 32, pp. 353-380.

[4] Areeda, Phillip E., Louis Kaplow, and Aaron S. Edlin, Antitrust Analysis: Problems, Text, and Cases, 7th Edition, Aspen Casebook, 2013.

[5] Bork, Robert, "Vertical Integration and the Sherman Act: The Legal History of an Economic Misconception," University of Chicago Law Review, 1954, 22 (1), pp. $157-201$

[6] Bowman, Ward S. Jr., "Tying Arrangements and the Leverage Problem," Yale Law Journal, 1957, 67, pp. 19-36

[7] Caillaud, Bernard and Bruno Jullien, "Chicken and Egg: Competition among Intermediation Service Providers," Rand Journal of Economics, Summer 2003, pp. 309-328.

[8] Carbajo, Jose, David De Meza, and Daniel J. Seidman, "A Strategic Motivation for Commodity Bundling," Journal of Industrial Economics, March 1990, 38, pp. 283-298.

[9] Carlton, Dennis, W. and Michael Waldman, "The Strategic Use of Tying to Preserve and Create Market Power in Evolving Industries," Rand Journal of Economics, Summer 2002, pp. 194-220.

[10] Chee, Foo Yun, "EU hits Google with second antitrust charge," Reuters, April 20, 2016, available at http://www.reuters.com/article/us-eu-google-antitrustidUSKCNOXHOVX.

[11] Chen, Yongmin, "Equilibrium product bundling," Journal of Business, 1997, 70, pp. $85-103$.

[12] Choi, Jay Pil, "Tying in Two-Sided Markets with Multi-Homing," Journal of Industrial Economics, 2010, 58 (3), pp. 607-626

[13] Choi, Jay Pil and Christodoulos Stefanadis, "Tying, Investment and the Dynamic Leverage Theory," Rand Journal of Economics, Spring 2001, pp. 52-71. 
[14] Director, Aaron and Edward H. Levi, "Law and the Future: Trade Regulation," Northwestern University Law Review, 1956, 51, pp. 281-296

[15] Edelman, Benjamin, "Does Google Leverage Market Power Through Tying and Bundling?," Journal of Competition Law $\&$ Economics, 2015, pp.365-400.

[16] Edelman, Benjamin and Damien Geradin, "Android and Competition Law: Exploring and Assessing Google's Practice in Mobile," October 2016, unpublished manuscript, available at http://www.benedelman.org/publications/google-mobile-201610-24.pdf.

[17] Farrell, Joseph and Nancy T. Gallini, "Second-Sourcing as a Commitment: Monopoly Incentives to Attract Competition," Quarterly Journal of Economics, 1988, pp. 673694.

[18] Hurkens, Sjaak, Doh-Shin Jeon, and Domenico Menicucci, "Leveraging Dominance with Credible Bundling," CEPR Discussion Paper, 2016.

[19] Jeon, Doh-Shin and Domenico Menicucci, "Bundling Electronic Journals and Competition among Publishers," Journal of the European Economic Association, 2006,.4 (5), pp. 1038-83.

[20] Jeon, Doh-Shin and Domenico Menicucci, "Bundling and Competition for Slots", American Economic Review, 2012, 102, pp. 1957-1985.

[21] Iacobucci, Edward M., "Tying in Two-Sided Markets, with Application to Google," unpublished manuscript, September 2014.

[22] Katz, Michael and Carl Shapiro, "Technology Adoption in the Presence of Network Externalities," Journal of Political Economy, 1986, 94, pp.822-841.

[23] Klemperer, Paul, "Competition when Consumers have Switching Costs," Review of Economic Studies, 1995, 62, pp. 515-539.

[24] Köszegi, Botond and Matthew Rabin, "A Model of Reference-Dependent Preferences," Quarterly Journal of Economics, 2006, pp.1133-1165.

[25] Newman, John M., "Antitrust in Zero-Price Markets: Foundations," The University of Pennsylvania Law Review, 2015, pp. 149-206.

[26] Newman, John M., "Antitrust in Zero-Price Markets: Applications," Washington University Law Review, 2016, 94 (1).

[27] Posner, Richard A., Antitrust Law: An Economic Perspective. Chicago: University of Chicago Press, 1976. 
[28] Posner, Richard A., "The Chicago School of Antitrust Analysis," The University of Pennsylvania Law Review, 1979, 127, pp 925-948

[29] Rochet, Jean-Charles and Jean Tirole, "Two-Sided Markets: A Progress Report," Rand Journal of Economics, 2006, pp. 645-667.

[30] Waldman, Michael, "A New Perspective on Planned Obsolescence, " Quarterly Journal of Economics, 1993, 108, pp. 273-284.

[31] Whinston, Michael D., 'Tying, Foreclosure and Exclusion,' American Economic Review, 1990, 80, pp. 837-859. 


\section{Appendix}

\section{Proof of Proposition 2}

We show that no firm has incentives to deviate at the putative equilibrium prices of $\widetilde{P}=u-\Delta$ and $\widetilde{p}_{2}=0$. When consumers are indifferent between buying the bundle only and buying firm 2's product only, we break the tie in favor of the bundle to avoid the open set problem: this is because firm 1 can decrease its price by $\varepsilon>0$, but firm 2 cannot because it is constrained by non-negative pricing. At these prices, a consumer's payoff is $v_{2}$ if he single-homes and buys only the bundle while his payoff is $v_{2}+\Delta-m$ if he multihomes. Therefore, only those consumers with $m \leq \Delta$ multihome in equilibrium.

Consider first the deviation of firm 2 to $\widetilde{p}_{2}>0$. A deviation to $\widetilde{p}_{2}>\Delta$ is obviously not optimal as firm 2 would have no demand. If $\widetilde{p}_{2} \leq \Delta$, the marginal consumer type who is indifferent between multihoming and not is given by $m^{*}=\Delta-\widetilde{p}_{2}$. With this deviation, firm 2's profit is given by

$$
\pi_{2}\left(\widetilde{p}_{2} ; \widetilde{P}=u-\Delta\right)=\left(\widetilde{p}_{2}+\beta\right) G\left(\Delta-\widetilde{p}_{2}\right)
$$

The first-order derivative is

$$
\frac{\partial \pi_{2}}{\partial \widetilde{p}_{2}}=G\left(\Delta-\widetilde{p}_{2}\right)-\left(\widetilde{p}_{2}+\beta\right) g\left(\Delta-\widetilde{p}_{2}\right) \leq 0,
$$

when it is evaluated at $\widetilde{p}_{2}=0$ with the assumption of $G(\Delta) / g(\Delta) \leq \beta$. The log-concavity of $g$ guarantees that $\frac{\partial \pi_{2}}{\partial \widetilde{p}_{2}}<0$ when evaluated at all positive $\widetilde{p}_{2}$. Therefore, there is no profitable deviation for firm 2 .

Consider now a deviation by firm 1 . Its equilibrium profit from $\widetilde{P}=u-\Delta$ is $(u-\Delta)+$ $[1-G(\Delta)] \beta$. It has no incentive to decrease its price from the equilibrium price since it sells the bundle to all consumers. Consider a deviation to $\widetilde{P}>u-\Delta$. Then, all consumers prefer buying firm 2's product to buying the bundle. If a consumer multi-homes and also buys the bundle, his payoff increases by $(u-\widetilde{P}-m)$. Therefore, only consumers whose cost of multi-homing is less than $(u-\widetilde{P})$ multi-home. Firm 1's profit upon the deviation is $\widetilde{P} G(u-\widetilde{P})$, which cannot be larger than the profit under no tying, $u$. Hence, if firm 1 has an incentive to tie, such deviation is never profitable. Firm 1 has incentives to tie if $\widetilde{\Pi}_{1}=(u-\Delta)+[1-G(\Delta)] \beta \geq u=\Pi_{1}$, that is, if $[1-G(\Delta)] \beta>\Delta$.

\section{Proof of Lemma 1}


(i) If $\widetilde{P} \in\left[\widetilde{p}_{2}-\Delta, 1+\widetilde{p}_{2}-\Delta\right]$, firm 1's profit is

$$
\Pi_{1}\left(\widetilde{P}, \widetilde{p}_{2}\right)=\left(1-\left[\left(\widetilde{P}-\widetilde{p}_{2}\right)+\Delta\right]\right)(\widetilde{P}+\alpha+\beta)
$$

The first-order condition with respect to $\widetilde{P}$ is equivalent to

$$
\widetilde{P}=\frac{(1-\Delta)-(\alpha+\beta)+\widetilde{p}_{2}}{2} .
$$

For this to be the optimal, the condition $\widetilde{P}=\frac{(1-\Delta)-(\alpha+\beta)+\widetilde{p}_{2}}{2} \geq \max \left\{0, \widetilde{p}_{2}-\Delta\right\}$ needs to be satisfied.

When $0 \leq \widetilde{P}<\widetilde{p}_{2}-\Delta$, firm 1's profit is

$$
\Pi_{1}\left(\widetilde{P}, \widetilde{p}_{2}\right)=(\widetilde{P}+\alpha+\beta)
$$

Hence, it is optimal to choose $\widetilde{P}=\max \left\{0, \widetilde{p}_{2}-\Delta\right\}$ given the non-negative price constraint.

Therefore, the best response is $\widetilde{P}=\frac{(1-\Delta)-(\alpha+\beta)+\widetilde{p}_{2}}{2}$ for $\Delta+[1-(\alpha+\beta)] \geq \widetilde{p}_{2}>$ $\Delta-[1-(\alpha+\beta)]$. If $1 \leq \alpha+\beta$ or for $\widetilde{p}_{2} \notin[\Delta+[1-(\alpha+\beta)], \Delta-[1-(\alpha+\beta)]$, it is optimal to choose $\widetilde{P}=\max \left\{0, \widetilde{p}_{2}-\Delta\right\}$.

(ii) Firm 2's profit is zero if $0 \leq \widetilde{P}<\widetilde{p}_{2}-\Delta$. If $\widetilde{P} \geq \widetilde{p}_{2}-\Delta$, its profit is

$$
\pi_{2}\left(\widetilde{P}, \widetilde{p}_{2}\right)=\left[\left(\widetilde{P}-\widetilde{p}_{2}\right)+\Delta\right]\left(\widetilde{p}_{2}+\beta\right)
$$

The first-order condition with respect to $\widetilde{p}_{2}$ yields

$$
\left[\left(\widetilde{P}-\widetilde{p}_{2}\right)+\Delta\right]-\left(\widetilde{p}_{2}+\beta\right)=0,
$$

which can be rewritten as

$$
\widetilde{p}_{2}=\frac{(\Delta-\beta)+\widetilde{P}}{2}
$$

For this to be the optimal, the condition for $\widetilde{p}_{2}=\frac{(\Delta-\beta)+\widetilde{P}}{2} \leq \widetilde{P}+\Delta$ needs to be satisfied, i.e., $\widetilde{P} \geq-(\Delta+\beta)$, which holds always. We can thus write the best response of firm 2 as

$$
B R_{2}(\widetilde{P})=\max \left[\frac{(\Delta-\beta)+\widetilde{P}}{2}, 0\right]
$$

\section{Proof of Lemma 2}


It is omitted as it is straightforward from the explanations in the main text.

\section{Proof of Lemma 3}

In this case, it can be easily shown that $\widetilde{P}^{\circ}>\widetilde{p}_{2}^{\circ}$. Thus, the non-negative price constraint is binding first for the rival firm's price under tying. We thus have

$$
\widetilde{P}^{*}=\frac{(1-\Delta)-(\alpha+\beta)}{2}, \widetilde{p}_{2}^{*}=0 .
$$

Firm 1 and firm 2's demands are respectively given by

$$
\widetilde{D}_{1}=\frac{(1-\Delta)+(\alpha+\beta)}{2}, \widetilde{d}_{2}=\frac{(1+\Delta)-(\alpha+\beta)}{2} .
$$

The corresponding profits are given by

$$
\widetilde{\Pi}_{1}=\left[\frac{(1-\Delta)+(\alpha+\beta)}{2}\right]^{2}, \widetilde{\pi}_{2}=\beta\left[\frac{(1+\Delta)-(\alpha+\beta)}{2}\right] .
$$

Since $\alpha<1-2 \Delta$ in the case we consider, firm 1's profit under no tying is $\Pi_{1}=\left(\frac{1+\alpha}{2}\right)^{2}$. Since $\beta>\Delta$ in this case, we have $\widetilde{\Pi}_{1}>\Pi_{1}$, that is, tying is profitable for the tying firm. In contrast, tying reduces the rival firm's profit. To see this, note that the rival firm's profit in the absence of tying is $\pi_{2}=\beta+\Delta>\beta>\beta\left[\frac{(1+\Delta)-(\alpha+\beta)}{2}\right]=\widetilde{\pi}_{2}$ because $(1+\Delta)-(\alpha+\beta)<2$ as $\beta>\Delta$.

\section{Proof of Lemma 4}

It is omitted as the proof of (i) and (ii) is provided in the main text and the proof of (iii) is straightforward.

\section{Proof of Lemma 5}

In this case, it can easily be shown that $\widetilde{P}^{\circ}<\widetilde{p}_{2}{ }^{\circ}$. Thus, the non-negative price constraint is binding first for the tying firm We thus have

$$
\widetilde{P}^{*}=0, \widetilde{p}_{2}^{*}=\frac{\Delta-\beta}{2} .
$$


Firm 1 and firm 2's demands are respectively given by

$$
\widetilde{D}_{1}=1-\frac{\Delta+\beta}{2}, \widetilde{d}_{2}=\frac{\Delta+\beta}{2} .
$$

The corresponding profits are given by

$$
\widetilde{\Pi}_{1}=(\alpha+\beta)\left[1-\frac{\Delta+\beta}{2}\right], \widetilde{\pi}_{2}=\left[\frac{\Delta+\beta}{2}\right]^{2} .
$$

We need to show that

$$
\widetilde{\Pi}_{1}=(\alpha+\beta)\left[1-\frac{\Delta+\beta}{2}\right]<\left\{\begin{array}{c}
\left(\frac{1+\alpha}{2}\right)^{2} \text { if } \alpha<1 \\
\alpha \text { if } \alpha>1
\end{array}\right.
$$

For $\alpha<1$,we use the following fact

$$
\left(\frac{x+y}{2}\right)^{2} \geq x y \text { for any } x \text { and } y \text {. }
$$

Let $x=\alpha+\beta$ and $y=1-\frac{\Delta+\beta}{2}$. Then, we have

$$
(\alpha+\beta)\left[1-\frac{\Delta+\beta}{2}\right]<\left(\frac{2+2 \alpha+\beta-\Delta}{4}\right)^{2} .
$$

Since $\beta<\Delta$ in this case, we have $\left(\frac{2+2 \alpha+\beta-\Delta}{4}\right)^{2}<\left(\frac{1+\alpha}{2}\right)^{2}$. Therefore, $\widetilde{\Pi}_{1}=(\alpha+$ в) $\left[1-\frac{\Delta+\beta}{2}\right]<\left(\frac{1+\alpha}{2}\right)^{2}=\Pi_{1}$ if $\alpha<1$.

For $\alpha>1$, tying is profitable only when $(\alpha+\beta)\left[1-\frac{\Delta+\beta}{2}\right]>\alpha$. This condition can be rewritten as

$$
\Delta<\frac{2 \beta}{\alpha+\beta}-\beta
$$

Since $\beta<\Delta$, the condition above can be satisfied only when $\beta<\frac{2 \beta}{\alpha+\beta}-\beta$, or $(\alpha+\beta)<1$, which is impossible because $\alpha>1$. Therefore, tying cannot be profitable for $\alpha>1$, either.

Tying obviously hurts firm 2 as tying reduces its price and market share.

\section{Proof of Lemma 6}

In market $A$, all consumers whose valuations satisfy $u \geq \frac{1-\alpha}{2}$ purchase product A. With tying, all consumers whose valuations satisfy $u \geq\left(1-\widetilde{D}_{1}\right)$ consume product A, where $\widetilde{D}_{1}$ denotes the bundle demand for firm 1 . Thus, for market $A$ to expand we need 
$\frac{1-\alpha}{2}>\left(1-\widetilde{D}_{1}\right)$. We can easily verify that this condition is equivalent to $\alpha<1-2 \Delta$ by checking all possible equilibrium price configurations with tying.

\section{Proof of Proposition 5}

- $\widetilde{P}^{*}=0, \widetilde{p}_{2}^{*}=0$

Consider a situation in which the post-tying equilibrium prices are zero $\left(\widetilde{P}^{*}=0, \widetilde{p}_{2}^{*}=\right.$ $0)$. Because $\widetilde{D}_{1}=1-\Delta$ in this case, the social welfare change with tying $(\Delta W)$ can be written as

$$
\Delta W=\int_{\Delta}^{\frac{1-\alpha}{2}}(u+\alpha) d u-(1-\Delta) \Delta
$$

We can easily see that if $\Delta$ is sufficiently small, then social welfare loss in market $B$ from tying is negligible. Thus, if $\beta$ is sufficiently large, firm 1 has incentives to capture market $B$ with tying, and tying can be socially beneficial as the market expansion effects in market $A$ outweigh social welfare loss in market $B .^{35}$

Consumer welfare in this case always increases because now both goods are provided for free.

- $\widetilde{P}^{*}>0, \widetilde{p}_{2}^{*}=0$

In this case, $\widetilde{D}_{1}=\frac{(1-\Delta)+(\alpha+\beta)}{2}$. By proceeding in a similar way as above, we can verify that if $\Delta$ is sufficiently small, tying can increase welfare. Otherwise, tying decreases welfare. It can also be shown that market $A$ always expands with tying as $\frac{1-\alpha}{2}>1-\widetilde{D}_{1}$ in this case.

Concerning consumer welfare, we can easily verify that $\widetilde{P}^{*}=\frac{(1-\Delta)-(\alpha+\beta)}{2}<p^{m}=\frac{1-\alpha}{2}$, i.e., the bundled product is even cheaper than the stand-alone $A$ product price before tying. As a result, consumers benefit from tying.

- $\widetilde{P}^{*}>0, \widetilde{p}_{2}^{*}>0$

In this case, $\widetilde{D}_{1}=\frac{2+\alpha-\Delta}{3}$. Once again, if $\Delta$ is sufficiently small, tying can increase welfare. Otherwise, tying decreases welfare.

\section{Proof of Proposition 6}

\footnotetext{
${ }^{35}$ We can also show that if $\Delta>1 / 7$, tying reduces welfare regardless of the value of $\alpha$.
} 
To derive the equilibrium prices under tying, note that firm 1's and firm 2's total profits are respectively given by

$$
\begin{gathered}
\widetilde{\Pi}_{1}\left(\widetilde{P}, n_{1}^{c}\left(\widetilde{P}, \widetilde{p}_{2}\right)\right)=(\widetilde{P}+\alpha) n_{1}^{c}+\underbrace{\left(\frac{\beta_{a} n_{1}^{c}}{2}\right)^{2}}_{\text {Profit from the App Side }} ; \\
\widetilde{\pi}^{2}\left(\widetilde{p}_{2}, n_{2}^{c}\left(\widetilde{P}, \widetilde{p}_{2}\right)\right)=\widetilde{p}_{2} n_{2}^{c}+\left(\frac{\beta_{a} n_{2}^{c}}{2}\right)^{2}
\end{gathered}
$$

Firm 1's first-order condition for profit maximization is given by

$$
\begin{aligned}
\frac{\partial \widetilde{\Pi}_{1}}{\partial \widetilde{P}} & =n_{1}^{c}+\left[\widetilde{P}+\alpha+\frac{\left(\beta_{a}\right)^{2} n_{1}^{c}}{2}\right] \frac{\partial n_{1}^{c}}{\partial \widetilde{P}} \\
& =-\frac{1}{1-\beta_{c} \beta_{a}}\left[\widetilde{P}+\alpha-n_{1}^{c}\left(1-\beta_{c} \beta_{a}-\frac{\left(\beta_{a}\right)^{2}}{2}\right)\right]
\end{aligned}
$$

where $\frac{\partial n_{1}^{c}}{\partial \widetilde{P}}=-\frac{1}{1-\beta_{c} \beta_{a}}\left(=-\frac{\partial n_{2}^{c}}{\partial \widetilde{P}}\right)$. Using $\Psi \equiv 1-\beta_{c} \beta_{a}-\frac{\left(\beta_{a}\right)^{2}}{2}$, we can rewrite the expression above as

$$
\frac{\partial \widetilde{\Pi}_{1}}{\partial \widetilde{P}}=-\frac{1}{1-\beta_{c} \beta_{a}}\left[\widetilde{P}+\alpha-n_{1}^{c} \Psi\right] .
$$

If $\Psi<0$, we always have $\frac{\partial \widetilde{\Pi}^{1}}{\partial \widetilde{P}}<0$, implying that $\widetilde{P}=0$ is optimal in the interior equilibrium where $n_{2}^{c}>0$. In a tipping equilibrium with foreclosure where $n_{2}^{c}=0$, there is no market share to gain and hence it is not optimal to reduce the price further and we will have $\widetilde{P}=\widetilde{p}+(\eta-\Delta)$.

Similarly, firm 2's first-order condition for profit maximization is given by

$$
\begin{aligned}
\frac{\partial \widetilde{\pi}_{2}}{\widetilde{p}_{2}} & =n_{2}^{c}+\left[\widetilde{p}_{2}+\frac{\left(\beta_{a}\right)^{2} n_{2}^{c}}{2}\right] \frac{\partial n_{2}^{c}}{\widetilde{p}_{2}} \\
& =-\frac{1}{1-\beta_{c} \beta_{a}}\left[\widetilde{p}_{2}-n_{2}^{c} \Psi\right]
\end{aligned}
$$

where $\frac{\partial n_{2}^{c}}{\partial \widetilde{p}_{2}}=-\frac{1}{1-\beta_{c} \beta_{a}}$. Once again, if $\Psi<0$, we have $\frac{\partial \widetilde{\pi}_{2}}{\widetilde{p}_{2}}<0$, implying that $\widetilde{p}_{2}=0$ is optimal.

Note that the second-order derivatives for firm 1 and firm 2 are the same and given 
by:

$$
\frac{\partial^{2} \widetilde{\Pi}_{1}}{\partial \widetilde{P}^{2}}=\frac{\partial^{2} \widetilde{\pi}_{2}}{\partial \widetilde{p}_{2}^{2}}=-\frac{1}{1-\beta_{c} \beta_{a}}-\left[1-\frac{\left(\beta_{a}\right)^{2}}{2} \frac{1}{1-\beta_{c} \beta_{a}}\right] \frac{1}{1-\beta_{c} \beta_{a}} .
$$

They are negative if

$$
\left(\beta_{a}\right)^{2}<4\left(1-\beta_{c} \beta_{a}\right)
$$

which is equivalent to

$$
\beta_{c} \beta_{a}+\frac{1}{4}\left(\beta_{a}\right)^{2}<1
$$

We consider two cases depending on the magnitudes of intergroup externality parameters (i.e., the sign of $\Psi$ ).

Case 1. $\Psi<0$ (i.e., $\beta_{c} \beta_{a}+\frac{\left(\beta_{a}\right)^{2}}{2}>1$ )

In this case, the equilibrium prices are $\widetilde{p}_{2}^{*}=0$ and $\widetilde{P}^{*}=\max \{0, \eta-\Delta\}$ as $\frac{\partial \widetilde{\pi}_{2}}{\widetilde{p}_{2}}<0$. We can have two types of equilibria depending on the relative magnitude of $\eta$ and $\Delta$ : a tipping equilibrium or an interior equilibrium. We have the following lemma that characterizes equilibrium in this case.

Lemma 7. Suppose that $\Psi<0$. Then, we have $\widetilde{p}_{2}^{*}=0$.

(i) If $\eta>\Delta$, we have a tipping equilibrium in which $n_{2}^{c *}=0$ and $\widetilde{P}^{*}>0$.

(ii) If $\eta<\Delta$, we have an interior equilibrium with $n_{2}^{c *}>0$ and both prices being driven down to zero $\left(\widetilde{P}^{*}=\widetilde{p}_{2}^{*}=0\right)$, where

$$
\begin{aligned}
& n_{2}^{c *}=\frac{\Delta-\eta}{\left(1-\beta_{c} \beta_{a}\right)}>0 ; \\
& n_{1}^{c *}=1-n_{2}^{c *}=\frac{1-(\Delta+\eta)}{\left(1-\beta_{c} \beta_{a}\right)}>0 .
\end{aligned}
$$

Case 2. $\Psi \geq 0$ (i.e., $\beta_{c} \beta_{a}+\frac{\left(\beta_{a}\right)^{2}}{2} \leq 1$ )

We also consider two types of equilibria under tying in this case: a tipping equilibrium and an interior equilibrium. Note that in this case (i.e., when $\Psi \geq 0$ ), the second-order condition is always satisfied in each firm's maximization problem.

Tipping Let us first analyze the possibility of a tipping equilibrium. In a tipping equilibrium with $n_{2}^{c *}=0$, we have the following first-order condition for firm 2 :

$$
\frac{\partial \widetilde{\pi}_{2}}{\widetilde{p}_{2}}=-\frac{\widetilde{p}_{2}}{1-\beta_{c} \beta_{a}} \leq 0 .
$$


Hence, $\widetilde{p}_{2}^{*}=0$. Then, the highest $\widetilde{P}$ consistent with tipping is $\widetilde{P}^{*}=\max \{0, \eta-\Delta\}$. At this price, firm 1 must have no incentive to deviate; the first-order derivative must be zero or negative.

If $\eta<\Delta$, the equilibrium prices in a tipping equilibrium need to be $\widetilde{P}^{*}=\widetilde{p}_{2}^{*}=0$. However, at these prices firm 2 has a strictly positive market share. We thus have a contradiction and there cannot be a tipping equilibrium if $\eta<\Delta$.

If $\eta \geq \Delta$, then $\widetilde{P}^{*}=\eta-\Delta$ and the following condition must hold:

$$
\frac{\partial \widetilde{\Pi}_{1}}{\widetilde{P}}=-\frac{1}{1-\beta_{c} \beta_{a}}[\eta-\Delta+\alpha-\Psi] \leq 0,
$$

which is equivalent to

$$
\alpha \geq(\Delta-\eta)+\Psi
$$

Summarizing, we have:

Lemma 8. Suppose that $\Psi \geq 0$. There is a tipping equilibrium in which $\widetilde{P}^{*}=\eta-\Delta \geq$ $p^{*}=0$ if $\eta \geq \Delta$ and $\alpha \geq(\Delta-\eta)+\Psi$, where $\Psi=1-\beta_{c} \beta_{a}-\frac{\left(\beta_{a}\right)^{2}}{2}$.

Interior Equilibrium Let us look for an interior equilibrium (i.e., each firm has a positive market share): $0<n_{2}^{c *}<1$. For an interior equilibrium, firm 2's first-order condition for profit maximization is given by

$$
\widetilde{p}_{2}^{*}=n_{2}^{c *} \Psi>0
$$

However, $\widetilde{P}^{*}$ can be zero. From firm 1's first-order condition, we have:

$$
\widetilde{P}^{*}=\max \left\{0,-\alpha+n_{1}^{c *} \Psi\right\}
$$

Consider the case of $\widetilde{P}^{*}=0$. Then, from the demand function and (5), we have

$$
n_{2}^{c *}=\frac{(\Delta-\eta)-n_{2}^{c *} \Psi}{\left(1-\beta_{c} \beta_{a}\right)}
$$

By collecting terms in $n_{2}^{c *}$, we have

$$
n_{2}^{c *}=\frac{\Delta-\eta}{\Psi+\left(1-\beta_{c} \beta_{a}\right)} .
$$


$\widetilde{P}^{*}=0$ is an equilibrium price for firm 1 if

$$
n_{1}^{c *} \Psi \leq \alpha,
$$

which is equivalent to

$$
\left[1-\frac{\Delta-\eta}{\Psi+\left(1-\beta_{c} \beta_{a}\right)}\right] \Psi \leq \alpha .
$$

If (6) is violated, then

$$
\widetilde{P}^{*}=-\alpha+n_{1}^{c *} \Psi>0 .
$$

Then,

$$
\widetilde{P}^{*}-\widetilde{p}_{2}^{*}=\left(1-2 n_{2}^{c *}\right) \Psi-\alpha .
$$

Putting this into the market share equation leads to

$$
n_{2}^{c *}\left(1-\beta_{c} \beta_{a}\right)=(\Delta-\eta)+\left(1-2 n_{2}^{c *}\right) \Psi-\alpha,
$$

which can be rewritten as

$$
n_{2}^{c *}\left[3 \Psi+\frac{\left(\beta_{a}\right)^{2}}{2}\right]=(\Delta-\eta)-\alpha+\Psi .
$$

Therefore,

$$
\begin{aligned}
n_{2}^{c *} & =\frac{(\Delta-\eta)-\alpha+\Psi}{3\left[\Psi+\frac{\left(\beta_{a}\right)^{2}}{6}\right]} \\
& =\frac{\frac{3}{2}\left[\Psi+\frac{\left(\beta_{a}\right)^{2}}{6}\right]-\frac{1}{2}+\Delta-\alpha}{3\left[\Psi+\frac{\left(\beta_{a}\right)^{2}}{6}\right]} \\
& =\frac{1}{2}-\frac{1+2 \alpha-2 \Delta}{6 \Psi+\left(\beta_{a}\right)^{2}}
\end{aligned}
$$

Hence, firm 1's market share is

$$
n_{1}^{c *}=1-n_{2}^{c *}=\frac{1}{2}+\frac{1+2 \alpha-2 \Delta}{6 \Psi+\left(\beta_{a}\right)^{2}} .
$$

Because we assume $\Psi=1-\beta_{c} \beta_{a}-\frac{\left(\beta_{a}\right)^{2}}{2}>0$, the denominator in the market share 
expression is strictly positive. Under the maintained assumption of $\Delta<1 / 2$, firm 1 's market share is larger than $1 / 2$, which is the market size in the monopolized market $A$ without tying when it is one-sided (i.e., when $\alpha=0$ ). The market share for firm 1 increases with $\alpha$ and decreases with $\Delta$, as expected. The market share's response to $\alpha$ or $\Delta$ is greater as the intergroup externalities in market $B$ becomes more important (i.e., as $\beta_{c}$ or $\beta_{a}$ increases).

Firm 1's equilibrium price is

$$
\begin{aligned}
\widetilde{P}^{*} & =-\alpha+n_{1}^{c *} \Psi \geq 0 . \\
& =-\alpha+\frac{\Psi}{2}+\frac{(1+2 \alpha-2 \Delta) \Psi}{6 \Psi+\left(\beta_{a}\right)^{2} .}
\end{aligned}
$$

We find

$$
\begin{gathered}
\frac{\partial \widetilde{P}^{*}}{\partial \alpha}=-1+\frac{2 \Psi}{6 \Psi+\frac{\left(\beta_{a}\right)^{2}}{2}} \\
=-\frac{4 \Psi+\left(\beta_{a}\right)^{2}}{6 \Psi+\left(\beta_{a}\right)^{2}}<0 . \\
\frac{\partial \widetilde{P}^{*}}{\partial \Delta}<0 . \\
\frac{\partial \widetilde{P}^{*}}{\partial \beta_{c}=} n_{1}^{c *} \frac{\partial \Psi}{\partial \beta_{c}}+\Psi \cdot \frac{\partial n_{1}^{c *}}{\partial \beta_{c}} \\
=-\beta_{a}\left[\frac{1}{2}+\frac{1+2 \alpha-2 \Delta}{6 \Psi+\left(\beta_{a}\right)^{2}}\right]+\Psi \cdot \beta_{a} \frac{1+2 \alpha-2 \Delta}{6\left[\Psi+\frac{\left(\beta_{a}\right)^{2}}{6}\right]^{2}} \\
=-\beta_{a}\left[\frac{1}{2}+\frac{1+2 \alpha-2 \Delta}{6\left[\Psi+\frac{\left(\beta_{a}\right)^{2}}{6}\right]}\left[1-\frac{\Psi}{\left.\left.\Psi+\frac{\left(\beta_{a}\right)^{2}}{6}\right]\right]<0 .}<\right.\right.
\end{gathered}
$$

Firm 2's equilibrium price is

$$
\begin{aligned}
\tilde{p}_{2}^{*} & =n_{2}^{c *} \Psi \\
& =\left(\frac{1}{2}-\frac{1+2 \alpha-2 \Delta}{6 \Psi+\left(\beta_{a}\right)^{2}}\right) \Psi .
\end{aligned}
$$

For a given market share, $\beta_{c} \beta_{a}>0$ induces firm 2 to charge a lower price to consumers 
for product $B$ than when $\beta_{c} \beta_{a}=0$. In addition, as long as $1+2 \alpha-2 \Delta>0$, firm 2's market share is smaller when $\beta_{c} \beta_{a}>0$ than when $\beta_{c} \beta_{a}=0$. Hence, both factors would induce firm 2 to become more aggressive.

Summarizing, we have:

Lemma 9. Suppose that $\Psi \geq 0$ and the conditions for the tipping equilibrium in Lemma 8 are not met. Then, there is an interior equilibrium such that

(i) if (6) is satisfied, $\widetilde{P}^{*}=0, \widetilde{p}_{2}^{*}=n_{2}^{c *} \Psi>0$ and

$$
n_{2}^{c *}=\frac{\Delta-\eta}{2 \Psi+\frac{\left(\beta_{a}\right)^{2}}{2}} .
$$

(ii) if (6) is violated, $\widetilde{P}^{*}=-\alpha+\left(1-n_{2}^{c *}\right) \Psi>0, \widetilde{p}_{2}^{*}=n_{2}^{c *} \Psi>0$ and

$$
n_{2}^{c *}=\frac{1}{2}-\frac{1+2 \alpha-2 \Delta}{6 \Psi+\left(\beta_{a}\right)^{2}}
$$

All the results in lemmas 7-9 we derived under different parameter configurations can be summarized as in Proposition 6. 